\title{
LA COMPATIBILIDAD ENTRE LOS DOS PROCEDIMIENTOS DE DECLARACIÓN DE INCONSTITUCIONALIDAD DEL TÍTULO II DE LA LOTC. LOS ARTÍCULOS 29.2 Y 38.2 LOTC Y LA EFICACIA DE LA SENTENCIA CONSTITUCIONAL
}

AUGUSTO MARTÍN DE LA VEGA

Universidad de Salamanca 


\section{SUMARIO}

1. INTRODUCCIÓN. 2. LA TRAMITACIÓN PARLAMENTARIA DE LOS ARTÍCULOS 29.2 Y 38.2 DE LA LOTC. LA "MENS LEGISLATORIS". 3. EL DEBATE DOCTRINAL EN TORNO A LOS ARTÍCULOS 29.2 Y 38.2 DE LA LOTC. 4. LA JURISPRUDENCIA DEL Tribunal Constitucional sobre el artículo 38.2 de LA LOTC. 5. ConcluSIONES. 


\title{
LA COMPATIBILIDAD ENTRE LOS DOS PROCEDIMIENTOS DE DECLARACIÓN DE INCONSTITUCIONALIDAD DEL TÍTULO II DE LA LOTC. LOS ARTÍCULOS 29.2 Y 38.2 LOTC Y LA EFICACIA DE LA SENTENCIA CONSTITUCIONAL
}

\author{
POR \\ AUGUSTO MARTÍN DE LA VEGA \\ Universidad de Salamanca
}

1. INTRODUCCIÓN

En uno de sus más recientes trabajos sobre la jurisdicción constitucional, Rubio Llorente mantenía que, junto a la aparente atribución de una eficacia general a la sentencia desestimatoria por el art. 38.1 LOTC, "el hecho de que, pese a la fuerza de cosa juzgada que tanto la CE como la LOTC (art. 38.1) atribuyen a las sentencias dictadas en los procedimientos de inconstitucionalidad, la propia LOTC (art. 29.2 y 38.2 ), abra la posibilidad de que sea cuestionada de nuevo la constitucionalidad de aquellas leyes frente a las que se han presentado recur- 
sos, suscita problemas que la doctrina aún no ha resuelto de manera generalmente aceptada" ${ }^{1}$.

Las afirmaciones del que fuera magistrado del Tribunal Constitucional no sólo son una señal inequívoca de las evidentes dificultades que implica cualquier intento de construir una "dogmática" sobre la sentencia constitucional y sus efectos ${ }^{2}$. Lo son también de la relación que la doctrina siempre ha establecido entre la existencia en nuestro ordenamiento de dos vías de impugnación de la constitucionalidad de las leyes, y el predicado valor de cosa juzgada del pronunciamiento sobre la norma legal.

En efecto, parecía claro que el establecimiento conjunto de un recurso y una cuestión inconstitucional que, aun guardando una «identidad teleológica ${ }^{3}$, presentan sin embargo importantes diferencias en cuanto a su sentido y función dentro del control de constitucionalidad, iba a determinar la aparición inmediata de la pregunta sobre su posible compatibilidad, o más precisamente, sobre su posible utilización sucesiva.

Por las características propias del control concentrado de constitucionalidad, el supuesto tan sólo se plantea realmente en torno a la supuesta eficacia impeditiva de una sentencia desestimatoria, bien de un recurso, bien de una cuestión de inconstitucionalidad, a la hora de elevar una duda o una impugnación de inconstitucionalidad sobre un mismo texto legal. Surgirá así el problema de si la utilización sin resultados positivos de una vía de impugnación cerraría definitivamente la posibilidad de acudir posteriormente al otro tipo de procedimiento para intentar de nuevo poner en cuestión la norma con valor de ley.

1 «La jurisdicción constitucional en España», en Estudios sobre jurisdicción constitucional. (con JiMÉNEZ CAMPO), Madrid, 1998, pág. 11.

2 Vid., por todos, RUBIo LLORENTE, "La jurisdicción constitucional como forma de creación del derecho", en La forma del poder (Estudios sobre la Constitución). Madrid, 1993, págs. 495 y ss., o GarrorenA, "Artículo 164", en Comentarios a la Constitución española de 1978 (O. Alzaga, dir.), XII, Madrid, 1999, págs. 333 y ss.

3 Según la muy conocida STC 17/81, de 1 de junio, citada repetidamente por el propio Tribunal.

4 Vid., por todos, JIMÉnEZ CAMPO, "Consideraciones sobre el control de constitucionalidad de la ley en el derecho español", en La Jurisdicción Constitucional en España. La Ley Orgánica del Tribunal Constitucional en España: 19791994, Madrid, 1995, págs. 74-86. 
Dados los plazos del recurso de inconstitucionalidad, y del conflicto en defensa de la autonomía local, y teniendo en cuenta también el tiempo habitual de resolución de los litigios por parte del Tribunal Constitucional ${ }^{5}$, la hipótesis del planteamiento de un recurso tras la emisión de una sentencia desestimatoria de una cuestión de inconstitucionalidad se convierte en meramente académica. El debate se centrará por tanto en la posibilidad de plantear una cuestión de inconstitucionalidad tras el pronunciamiento desestimatorio de un inicial recurso 6 .

Es evidente que la respuesta a esta pregunta puede afectar a la determinación de cuál sea el efecto de cosa juzgada de la sentencia constitucional. Una decisión previa del legislador constitucional u orgánico que estableciera una incompatibilidad absoluta entre los dos procedimientos haría inútil la pregunta acerca de los límites del «iudicato" constitucional, en cuanto, aunque estos no se dieran, la sentencia gozaría de inmutabilidad frente al planteamiento de una posterior cuestión de inconstitucionalidad.

Por otra parte, la posible opción legislativa a favor de la compatibilidad entre el recurso y la cuestión de inconstitucionalidad suscitaría el problema del alcance de dicha compatibilidad. Si ésta fuera absoluta, esto es, si tras la desestimación de un recurso pudiera plan-

5 Como es sabido el Alto Tribunal decidió desde muy pronto interpretar de manera flexible las disposiciones específicas de la LOTC al respecto (art. 34.2 y 37.2). El problema de las consecuencias prácticas que acarrea este alargamiento "de facto" en el plazo de resolución de las dudas sobre la constitucionalidad de la ley, fruto sin duda de la sobre carga del Tribunal en otros campos, merecería quizás una atención más específica por parte de la doctrina. Que el término medio para resolver un recurso de inconstitucionalidad sea de dos años, aunque haya ido disminuyendo en tiempos más recientes, es quizás una de las razones que explican la necesidad en que se encuentra el TC de modular los efectos de sus pronunciamientos. Las implicaciones teóricas de esta situación son sin duda decisivas, y abarcan desde el replanteamiento del propio concepto de inconstitucionalidad, vid. JIMÉNEZ CAMPO, "Qué hacer con la ley inconstitucional", en Las sentencias sobre la inconstitucionalidad de la ley, Madrid, 1997, hasta la redefinición del papel del Tribunal en relación con el Parlamento, por todos E. AJA (ed.), Las Tensiones entre el Tribunal Constitucional y el Legis/ador en la Europa actual. Barcelona, 1998, o GoNZÁLEZ BEILfuSS, Tribunal Constitucional y reparación de la discriminación normativa, Madrid, 2000.

6 Aunque derivará también, como veremos, hacia el problema de la posibilidad de plantear sucesivas cuestiones de inconstitucionalidad sobre una misma norma legal, aspecto éste donde nos alejamos del tema de la compatibilidad entre las dos vías de impugnación para entrar estrictamente en el terreno de la eficacia de cosa juzgada de las sentencias constitucionales. 
tearse una duda de inconstitucionalidad idéntica a la ya resuelta desfavorablemente 7 , entonces podría mantenerse en este caso, que o bien la primera sentencia carece de fuerza de cosa juzgada, o bien que a los límites tradicionales del "iudicato" habría que añadir para el control de las leyes uno específico, el de que no nos encontraríamos ante el ejercicio de una vía procesal distinta.

Pero podría entenderse también que la legislación prevé tan sólo la simple compatibilidad genérica entre las dos vías, en atención a su respectiva función dentro del control de constitucionalidad, y que ante la elevación de una cuestión tras la sentencia desestimatoria del recurso de inconstitucionalidad, deban operar los efectos previstos por la Constitución y la propia LOTC respecto a las sentencias constitucionales, en este caso su fuerza de cosa juzgada. Cosa juzgada que aquí sería eficaz, como es lógico, siempre que se den los límites objetivos y subjetivos que la definen. Quedaría así abierto el problema de determinar estos límites desde la dogmática de la jurisdicción constitucional, aun teniendo en cuenta que cualquier teoría sistematizadora de la "res iudicata" de los pronunciamientos del Tribunal debería ser coherente con esta posibilidad de replanteamiento, prevista expresamente por la ley.

El problema surge, sin embargo, cuando el legislador decide regular la compatibilidad entre los diferentes procedimientos de control, y al hacerlo, establece, como hace en la LOTC, una normativa, cuando menos, indirecta, fragmentaria y confusa ${ }^{8}$.

7 Idéntica, en cuanto se impugnara la misma disposición por oposición al mismo parámetro y con la misma motivación, y siempre, claro está, que el factor temporal no determinara un cambio real en la interpretación de las normas en conflicto.

8 Como veremos, la opinión negativa sobre la regulación prevista en la LOTC es ampliamente mayoritaria y de tonos fuertemente críticos; así, por ejemplo, del art. 29,2 se ha dicho que "se adentra casi en el terreno del absurdo" (RuBio Y ARAGón, «La Justicia Constitucional», en La Constitución española de 1978. Estudio sistemático, Madrid, 1980, pág. 87), que es «incompleta y de redacción confusa" (BOCANEGRA, El valor de las Sentencias del Tribunal Constitucional, Madrid, 1982, pág. 139), "discutido y discutible" (PIBERNAT DOMÉNECH, "La sentencia constitucional como fuente del derecho", en RDP, 1987, pág. 63), "manifiestamente inconstitucional" (García de Enterria/T. R. Fernández, Curso de Derecho Administrativo, Madrid, 1997, pág. 161) o de "deficiente redacción" (E. EsPíN, "Artículo 29.2», en Comentarios a la Ley Orgánica del Tribunal Constitucional, coord. Requejo Pagés, Madrid, 2001, pág. 440). La regulación completa de los arts. 38.2 y 29.2 es calificada por BOCANEGRA, op. cit., págs. 255 y 258, entre otras, como «inadmisible, completamente inconstitucional e incoherente", 0 , en términos menos rotundos, de 
Así el artículo 29.2 LOTC, dentro del Capítulo l, «Disposiciones Generales", del título II "De los procedimientos de declaración de inconstitucionalidad", indica que "La desestimación, por razones de forma, de un recurso de inconstitucionalidad contra una ley, disposición o acto con fuerza de ley no será obstáculo para que la misma.ley, disposición o acto puedan ser objeto de una cuestión de inconstitucionalidad con ocasión de su aplicación en otro proceso».

Por su parte, el artículo 38.2, ya dentro del Capítulo IV del mismo título, "De la sentencia en procedimientos de inconstitucionalidad $y$ de sus efectos", preveía originariamente que "Las sentencias desestimatorias dictadas en recursos de inconstitucionalidad impedirán cualquier planteamiento ulterior de la cuestión en la misma vía, fundado en infracción de idéntico precepto constitucional». Tras la Ley Orgánica 7/1999 de 21 de abril, que introduce el llamado conflicto en defensa de la autonomía local, el art. 38.2 establece actualmente que " Las sentencias desestimatorias dictadas en recursos de inconstitucionalidad y en conflictos en defensa de la autonomía local impedirán cualquier planteamiento ulterior de la cuestión por cualquiera de las dos vías, fundado en infracción de idéntico precepto constitucional» ${ }^{9}$.

De una primera lectura de ambos artículos se pueden ya deducir una serie de puntos problemáticos. En primer lugar destaca su colocación en distintos capítulos de la LOTC, de tal forma que, o bien nos encontramos ante simple falta de rigor sistemático por parte del legis:lador $^{10}$, o cabría entender que el art. 29.2 regula específicamente la compatibilidad entre los dos recursos, siendo el art. 38.2 una especificación de determinados efectos de las sentencias en el procedimiento de control en general. En segundo lugar destaca el hecho de que ambos artículos aludan a las desestimaciones de recursos de incons-

"redacción poco afortunada», por GómEz MONTORO, "Artículo 38.2", en Comentarios a la Ley Orgánica del Tribunal Constitucional, op. cit., pág. 547.

9 Como señala Gómez MONTORo, al introducir la nueva vía de declaración de inconstitucionalidad de una ley del conflicto en defensa de la autonomía local, "se perdió sin embargo la ocasión de modificar más a fondo el precepto...eliminando definitivamente toda su ambigüedad", "Art. 38", en Comentarios..., op. cit., pág. 574. Con la nueva redacción debe desaparecer no obstante una de las dudas menores sobre el artículo. Ya queda claro que al hablar de "la misma vía", ahora de las "dos vías", se está haciendo referencia a la posibilidad de un nuevo recurso de inconstitucionalidad o de un nuevo conflicto sobre la autonomía local.

10 Por todos, PAstor Ridruejo, "Aplicación de la ley y control de constitucionalidad", en El Tribunal Constitucional, vol. I, Madrid, 1981, págs. 2024-2028. 
titucionalidad ${ }^{11}$. No se realiza ninguna mención por tanto a los posibles efectos de una sentencia desestimatoria de la cuestión de inconstitucionalidad, ya sea por razones de forma (y la consiguiente posibilidad o no de presentar un recurso, supuesto este, como vimos, harto improbable), o por motivos de fondo (con lo que queda sin resolver el problema no sólo de la hipotética sucesión entre cuestión y recurso, sino el mucho más práctico de la sucesión entre cuestiones de inconstitucionalidad).

Pero el problema principal que una primera aproximación a ambos artículos denota inmediatamente es el juego "perverso" que, desde el punto de vista interpretativo, suscita la combinación entre lo que textualmente se afirma y lo que parece dar a entenderse, entre lo que se deduce y lo deducible lógicamente por cualquier operador jurídico mínimamente atento ${ }^{12}$.

La afirmación del art. 29.2 LOTC de que la sentencia desestimatoria por razones de forma de un recurso de inconstitucionalidad "no será obstáculo" para que pueda plantearse una cuestión sobre la misma disposición, tiene su correlato en la "deducible» negación de la posibilidad de plantear la cuestión de inconstitucionalidad cuando nos encontremos ante una sentencia desestimatoria del recurso por motivos de fondo. Por el contrario, la afirmación del artículo 38.2 LOTC de que las sentencias desestimatorias de los recursos impedirán un nuevo recurso, fundado en infracción de idéntico precepto, parece llevar la "deducible» afirmación de la posibilidad de plantear la cuestión de inconstitucionalidad cuando nos encontremos ante una sentencia desestimatoria por razones de fondo del recurso de inconstitucionalidad ${ }^{13}$.

11 Si bien el art. 38.2 habla de "sentencias desestimatorias", la expresión del art. 29.2 "la desestimación" englobaría también a los autos, al tratarse de desestimaciones por razones de forma. Con la nueva regulación, el 38.2 alude, obviamente a la desestimación de recursos de inconstitucionalidad y de conflictos en defensa de la autonomía local. 441-2.

12 En el mismo sentido, Espín, «Art. 29.2», en Comentarios..., op. cit., págs.

13 Y, después de la L.O. 7/99, de una sentencia desestimatoria por razones de fondo de la inconstitucionalidad de la ley impugnada en el conflicto en defensa de la autonomía local. A los efectos de compatibilidad entre vías de impugnación,este "conflicto", que tiene por objeto la impugnación de una ley, queda equiparado al recurso de inconstitucionalidad. La asimilación parece lógica en cuanto los plazos de impugnación, si bien no idénticos a los del recurso, vid. art. 75 quater LOTC, son en todo caso igualmente reducidos. 
Se produce por tanto una "potencial" contradicción entre ambos artículos, que sin contradecirse en sus taxativas afirmaciones, sí parecen hacerlo en lo que tácitamente parecen, a su vez, prohibir y permitir respectivamente.

Una regulación de este tipo, en un tema de considerable importancia teórica y práctica, no podía menos que suscitar una amplia discusión doctrinal encaminada a clarificar desde categorías doctrinales el alcance y significado real de ambos artículos. La polémica se verá avivada a su vez por el hecho de encontrarnos ante uno de esos casos, claro como pocos, en que la intención del legislador es, como veremos, hasta cierto punto inequívoca, pero choca con lo que gran parte de la doctrina entiende que deberían ser los mínimos sistemáticos para un funcionamiento coherente y adecuado a sus fines del mecanismo del control de las leyes.

La libertad interpretativa que va a suponer la búsqueda de una "voluntad de la ley" claramente desligada de la "mens legislatoris", se acentuará por las importantes implicaciones teóricas que como intentamos explicar, subyacen a la polémica sobre la compatibilidad/ incompatibilidad entre las dos vías. Se produce así un fenómeno, hasta cierto punto original, por el cual las consideraciones de fondo sobre institutos como la cosa juzgada prejuzgan la elección interpretativa de los autores que se esfuerzan en hallar unas primeras explicaciones a la confusa regulación de la LOTC, para, pasado el tiempo, y consolidadas mayoritariamente determinadas interpretaciones, servir estas de apoyo argumentativo a ciertas conclusiones sobre la existencia y límites de la cosa juzgada en las sentencias constitucionales: Todo ello, junto con el hecho de que otros autores encuadren la regulación del art. 29.2 y 38.2 y su interpretación dentro del fenómeno de la cosa juzgada, nos induce a pensar que la exposición de la evolución de las posturas doctrinales sobre el tema puede resultar de especial interés.

Creemos también que en este caso quizás sea útil una atención específica a la "escasa jurisprudencia constitucional"14sobre este tema. Esta escasez a la que aludian García de Enterría y Tomás Ramón Fernández, y que hoy podría ser cuestionada, lo es más por su cantidad que por su importancia; si bien, y de ahí la utilidad de su estudio concreto, una mirada atenta a la misma nos llevará a extraer una con-

14 García de Enterría, Curso de derecho administrativo (4. ed.), págs. 171 y ss. 
clusiones mucho más matizadas de las que son de uso común en la doctrina ${ }^{15}$. Es cierto sin embargo que la jurisprudencia del Tribunal permite actualmente, con su valor vinculante, tener por seguros ciertos aspectos de la interpretación del art. 38.2 LOTC, que no lo estaban en el momento de su entrada en vigor.

Con todo ello, proceso de elaboración, debate doctrinal e interpretación jurisprudencial, intentaremos llegar a una fijación válida del real contenido normativo de los artículo 29.2 y 38.3 de la LOTC. Se trata por tanto de determinar qué es lo que realmente prescriben ambos artículos y cuál es el contenido deducido a su vez de los mismos por la labor interpretativa del Tribunal Constitucional.

15 No me resisto a señalar el curioso fenómeno de interacción legisladordoctrina-jurisprudencia que, desgraciadamente, se produce aquí más a título personal que como señal de una institucionalización más efectiva de la necesaria relación entre estos tres aspectos del mundo jurídico constitucional. Es curioso que dos de los redactores del inicial Proyecto de Ley de la LOTC, Rubio Llorente y Arozamena, Proyecto cuya orientación en este tema cambió sustancialmente el Parlamento, fueran a su vez dos de las voces críticas, el primero de ellos muy destacadamente, que se elevaron en la doctrina sobre el artículo 29.2 y 38.2 de la LOTC. Ambos a su vez desempeñarían una labor destacada como magistrados del Tribunal Constitucional cuando éste comenzó a interpretar dichos artículos. El paralelismo con el caso de Azzariti en Italia resulta también inevitable. También el ilustre jurista italiano jugó un papel destacado en la clasificación de la eficacia que debiera otorgarse a los pronunciamientos desestimatorios de la Corte Constitucional. Su refutación doctrinal de la pretendida eficacia de interpretación auténtica de la sentencia desestimatoria que sostuviera CALAMANDREI en su L Lillegittimità delle leggi nel processo civile, Padova 1950, págs. 96 y ss., fue decisiva, vid. así su "ll sindicato di costituzionalità delle leggi", en Riv. Dir. Proc. 1950, págs. 97 y ss. El propio CALAMANDREI terminará aceptando la posibilidad de replanteamiento de la cuestión tras una decisión desestimatoria en su "Corte costituzionale e autorità giudiziaria", en Riv. dir. proc. 1956, págs. 163 y ss. Por otra parte, tras la dimisión de De Nicola en marzo de 1957. Azzaritti puede considerarse realmente el primer presidente efectivo de la Corte, y participará por ello en la jurisprudencia que inmediatamente dejará claro la posibilidad de volver a replantear la constitucionalidad de una ley ya impugnada, vid. SSTC 8/1956, de 2 de julio, o 7/58, de 27 de enero, y las "Ordenanze» de 21 de julio de $1956 n .^{\circ} 23,2425$ y 27 y 28 . Como señala RugGIERI, Storia di un "falso". L'eficacia "inter partes" dellle sentenze di rigetto della Corte costituzionale, Milán, 1990, pág. 29, «se producirá así un movimiento en espiral, por la convergencia en un mismo sentido de la acción concorde de la doctrina y de la jurisprudencia que, en breve tiempo, llevará a una situación considerada ya como irreversible". 


\section{LA TRAMITACIÓN PARLAMENTARIA DE LOS ARTÍCULOS 29.2 Y 38.2 DE LA LOTC. LA «MENS LEGISLATORIS»}

Dados los resultados interpretativos a los que generalmente ha llegado la doctrina en su estudio de los dos artículos de la LOTC referidos a la relación entre el recurso y la cuestión de incrunstitucionalidad, no puede causar extrañeza la escasa atención que ésta ha dedicado al análisis del proceso de tramitación parlamentaria de ambas disposiciones ${ }^{16}$. Sin necesidad de compartir la solución que pretendió ofrecer el legislador, sí es cierto que determinar qué quiso establecer exactamente sobre la materia, puede arrojar algo de luz, dada la utortuosa" forma en que plasmó sus intenciones en el texto de la Ley Orgánica.

El proyecto de ley que el Gobierno presentó a las Cortes a principios de mayo de 197917 mantenía, como es sabido, una denominación genérica de "recurso de inconstitucionalidad", que se desdoblaba en un recurso por la vía principal, nuestro actual recurso de inconstitucionalidad propiamente dicho, y una "vía incidental" que a lo largo de la tramitación parlamentaria pasaría a denominarse "cuestión de inconstitucionalidad» ${ }^{18}$.

Respecto al concreto tema de la compatibilidad/incompatibilidad ente las dos vías, el Proyecto establecía dos artículos, el 32 y el 42 , ar-

16 Con algunas excepciones, como PASTOR RIDRUEJO, "Aplicación de la ley y control de constitucionalidad", op. cit., págs. 2025 y ss., y de ELIZALDE y AYMERICH, "El Tribunal Constitucional y la jurisprudencia», en El Tribunal Constitucional, v. I, Madrid, 1981, págs. 863 y ss., que evidentemente lo hacen por ser los que más se acercan al propósito inicial del legislador en su interpretación

17 Sobre las características de la LOTC, vid., entre otros, RUBio y ARAGón "La Jurisdicción Constitucional», op. cit.; GonzÁlez Pérez, Derecho Procesal Cons: titucional, Madrid, 1980, Almagro/SaAvedra Gallo, Justicia Constitucional. Comentarios a la Ley Orgánica del Tribunal Constitucional, Valencia, 1989; CANo MaTA, Comentarios a la Ley Orgánica del Tribunal Constitucional, Madrid, 1986; PULIDO QUeCEdo, Ley Orgánica del Tribunal Constitucional, Madrid, 1995; RUBIO LLORENTE, "La Jurisdicción Constitucional en España", en Estudios sobre jurisdicción consti tucional (con JiMÉnEz CAMPO), Madrid, 1998, o la "Introducción" de ReQueJo PAGÉs a los Comentarios a la Ley Orgánica del Tribunal Constitucional por él dirigidos, Madrid, 2001.

18 Producto de la enmienda número 26 de UCD en el Senado, y aceptado definitivamente en el Informe de la Ponencia, art. 29.1. Vid., Tribunal Constitucional. Trabajos Parlamentarios. Cortes Generales (Santamaría Pastor, ed.), Madrid, 1980. 
tículos que tras sucesivas modificaciones terminarían adoptando la actual redacción de los arts. 29.2 y 38.2 de la LOTC. En su artículo 32 se preveía que "...La desestimación de un recurso de inconstitucionalidad contra una ley, disposición o acto con fuerza de ley promovido en vía principal no será obstáculo para que la misma ley, disposición o acto puedan ser impugnadas en vía incidental con ocasión de su aplicación en otro proceso". El artículo 42.2 por su parte contemplaba que "Las sentencias que declaren la inconstitucionalidad de una ley, disposición o acto con fuerza de ley producirán efectos generales desde su publicación en el BOE. Las sentencias desestimatorias dictadas en recurso de inconstitucionalidad promovido en vía principal impedirán cualquier planteamiento ulterior de cuestión en la misma vía».

Prescindiendo por el momento del tratamiento conjunto en un mismo párrafo de las sentencias estimatorias y desestimatorias, con lo que suponía de implícita negación de los efectos generales de las sentencias desestimatorias al prever este efecto sólo para las que declaran la inconstitucionalidad de la ley, y de la ausencia en el artículo 42.1 de cualquier referencia al efecto de cosa juzgada consagrado en el artículo $164 \mathrm{CE}^{19}$, lo cierto es que el Proyecto de Ley dejaba

19 Así, el artículo 42.1 "Las sentencias recaidas en recurso de inconstitucionalidad producirán efectos una vez notificadas a las partes. Vincularán a todos los órganos del Estado y, en particular, cuando se trate de sentencias recaidas en recursos promovidos por vía incidental dentro de otros procesos, al órgano judicial competente para la decisión en este". La primera parte del art. 42.2 sobre el efecto general de las sentencias estimatorias, "Las sentencias que declaren la inconstitucionalidad de una ley, disposición o acto con fuerza de ley producirán efectos generales desde su publicación en el Boletín Oficial del Estadon, pasará al párrafo primero, perdiendo su referencia al tipo de sentencia y quedando su redacción definitiva plasmada en el Informe de la Ponencia, art 42.1 "Las sentencias recaidas en recursos de inconstitucionalidad tendrán el valor de cosa juzgada, vincularán a todos los poderes públicos y producirán efectos generales desde su publicación en el Boletín Oficial del Estado...". La redacción tiene su origen en la enmienda 172 del Grupo Catalán, que solicitaba la plasmación del art. 164 de la CE en este artículo, junto con el efecto de vinculación a todos los poderes públicos. Con ello, el art 42 , posteriormente 38.1 de la LOTC, acogía la siempre problemática tríada de efectos: cosa juzgada/ efectos generales/ vinculación a los poderes públicos, que a partir del art 31 de la BVerfGG de 1951 viene a encuadrar, como es sabido, el valor de las sentencias sobre la constitucionalidad de la ley en Alemania. Aun cuando este artículo no prevé textualmente un efecto de cosa juzgada para la sentencia constitucional, como tampoco lo hace la Ley Fundamental, el instituto es actualmente aceptado por la gran mayoría de la doctrina y expresamente reconocido por la jurisprudencia constitucional. Vid., por todos, K. SCHLAICH, Das Bundesverfassungsgerichts, München 1994, págs. 272-274; W. LöWER, "Zuständigkeiten und 
traslucir una sistemática coherente. Se prohibía legislativamente la sucesión de recursos de inconstitucionalidad, lo que no resultaba extraño dado el plazo de ejercicio de la impugnación y la finalidad de cese del debate sobre la legitimidad de la ley que en cierta manera el recurso de inconstitucionalidad está llamado a desempeñar ${ }^{20}$. Por otra parte se mantenía abierta la compatibilidad entre las dos vías básicas de acceso a la declaración de inconstitucionalidad de las normas con rango de ley, permitiendo el planteamiento de sucesivas cuestiones de inconstitucionalidad tras la sentencia desestimatoria del recurso directo. Se establecía en principio la impugnabilidad del texto ya examinado, sin mayores referencias a la necesidad de variar las causas de la impugnación. Era un intento obvio de permitir, a través del instrumento no sometido a tiempo que era la cuestión de inconstitucionalidad, la reconsideración de la constitucionalidad de determinadas normas tras el transcurso del tiempo.

El artículo del Proyecto recibirá sin embargo en el Congreso sucesivas enmiendas de los grupos parlamentarios socialista, catalán $y$ andalucista, $y$ todas ellas dirigidas a suprimir esta posibilidad de planteamiento de la cuestión de inconstitucionalidad tras la desestimación de un recurso. La enmienda $n .^{\circ} 20$ del grupo socialista propondrá la redacción que se plasmará finalmente en el Informe de la Ponencia bajo el artículo 32. Así, pretendía añadir las palabras «por razones de forma" al texto del art. 32, que concluiría "la desestimación, por razones de forma, de un recurso de inconstitucionalidad contra una ley, disposición o acto con fuerza de ley no será obstáculo para que la misma ley, disposición o acto puedan ser objeto de una cuestión de inconstitucionalidad con ocasión de su aplicación a otro proceso".

Su finalidad explícita era " limitar esta posibilidad a las desestimaciones por razones de forma». Se trataba de impedir que tras una sentencia desestimatoria por razones de fondo de un recurso se pudiera plantear una cuestión queda claro al comprobar la motivación de las Enmiendas del Grupo Catalán (Enmienda n. ${ }^{\circ} 163$ ) y Andalucista

Verfahren des Bundesverfassungsgerichts", en Handbuch des Staats Rechts, II (Isensee/Kirchhof Hrsg.), Heildelberg, 1987, págs. 794 y ss., o MAUNZ/SCMIDT-BLEIBTREU/ KLEIN/ULSAMER, Bundesverfassungsgerichtsgesetz, "Art 31", München, 1995, págs. 13 yss.

20 Vid. JIMÉNEz CAMPO, "El control de constitucionalidad dela ley en el derecho español", en Estudios sobre la jurisdicción constitucional (con RUBıo LLORENTE), Madrid, 1997, págs. 71-72. 
(Enmienda $n .^{\circ} 218$ ), tendentes a la supresión del art. 38.221. El grupo de Minoría Catalana argumentaba que "si la sentencia del TC tiene, según el art. 164 de la CE, el valor de cosa juzgada y produce efectos frente a todos, carece de sentido el párrafo que se propone suprimir (el entero art. 32.2, actual 29.2), cuyo mantenimiento abriría una peligrosa puerta a la seguridad jurídica». El del grupo andalucista era más escueto: el art. 32.2, "a eliminar por razón del efecto de $C J$ que debe producir el fallo originarion 22 . Creemos que ambas enmiendas debían ser transcritas porque gráficamente anticipan parte del debate doctrinal subsiguiente: la relación entre compatibilidad de vías y cosa juzgada, y la subyacente identificación del uiudicato" y los posibles efectos subjetivos generales del mismo como causa impeditiva de la admisión de una cuestión de inconstitucionalidad tras una sentencia desestimatoria de un recurso directo.

El Informe de la Ponencia no sólo acogerá la enmienda socialista sobre el art. $32.2^{23}$, sino que también modificará el texto del art. 42.1 (actual 38.2), en función de otra enmienda del mismo Grupo, la número 12, donde se solicitaba añadir a la dicción propuesta por el Proyecto la frase final, "por idéntico motivo de inconstitucionalidad", con lo que en cierta manera se relajaba la prohibición absoluta de impugnar por segunda vez una misma ley a través de un recurso de inconstitucionalidad. El texto definitivo de la Ponencia matizará sin embargo la flexibilización, al disponer la frase final "fundado en la vio-

21 Por su parte, la enmienda del Grupo Comunista número 253 pretendia también suprimir el art. 32.2, pero no ofrecia motivación. Curiosamente, en la Enmienda número 39 sobre el artículo 42.2 se proponía una redacción de difícil entendimiento: "Las sentencias que declaren la inconstitucionalidad de una ley, disposición o acto con fuerza de ley producirán efectos generales desde la fecha de su publicación en el BOE aunque no impedirán un ulterior pronunciamiento sobre la misma cuestión. Las sentencias desestimatorias dictadas en recursos de inconstitucionalidad —en sentido genérico-impedirán cualquier planteamiento ulterior de la cuestión".

81 y 100 .

22 Vid. Tribunal Constitucional. Trabajos Parlamentarios, op. cit., págs. 40,

23 Y por tanto optará por mantener el antiguo texto del art. 32.2, pero con la adición de la expresión "por razones de forma», que en el fondo implicaba cam. biar el inicial sentido del artículo, frente a la simple posibilidad, apuntada por las enmiendas catalana y andaluza, de suprimir directamente todo el texto. Cabe plantearse hipotéticamente si la Ponencia no consideraría que la supresión total del precepto dejaba en cierto modo "abierta" las posibilidades de presentación de una posterior cuestión y optó por mantener el texto, con el añadido de la desestimación "por razones de forma", para asegurar el carácter obstativo que todas las enmiendas pretendian. 
lación de idéntico precepto constitucional»24. Con ello el art. 42.1 mantenía en su segundo párrafo que "Las sentencias desestimatorias dictadas en recurso de inconstitucionalidad promovido en vía principal impedirán cualquier planteamiento ulterior de la cuestión en la misma vía, fundado en la infracción de idéntico precepto constitucionalı ${ }^{25}$.

El texto que llegará al Senado ${ }^{26}$ ha sufrido pues, respecto al Proyecto de Ley, dos adiciones textuales que, sin embargo, habían cambiado sustancialmente la regulación del actual art. 29.2, y, por ende, el sistema de compatibilidad/incompatibilidad entre el recurso y la cuestión de inconstitucionalidad.

En el Senado, tan sólo se presentarán dos enmiendas a estos artículos. La más importante será la del Grupo centrista (n. ${ }^{\circ} 37$ ), que reorganizará, al ser aceptada, el art. 38.1, dándole su actual redacción, y que también propondrá el cambio de la expresión del ahora art. 38.2, "fundado en la violación de idéntico precepto constitucional», expresión que no obstante será sostenida por la Ponencia y permanecerá en la redacción definitiva del art. $38.2^{27}$.

En el Informe de la Ponencia se mantendrá por tanto, básicamente, la redacción del Congreso de los Diputados. Sin embargo, el texto sufrirá una modificación decisiva en el Dictamen de la Comisión, que decidirá suprimir la frase del art. 29.2 "por razones de forma», con lo que se volvía a la redacción primitiva del Proyecto presentado por

24 La enmienda socialista se motivaba en un escueto "mejora técnica", que quizás hacia referencia a la posibilidad de que, partiendo del cumplimiento estricto de los plazos para dictar sentencias por parte del TC, la nueva redacción no impidiera sucesivos recursos de inconstitucionalidad por parte del mismo grupo de parlamentarios o de otros tras una primera sentencia desestimatoria. En todo caso parece que la decisión final de la Ponencia, aún levantando la prohibición absoluta de recursos de inconstitucionalidad sucesivos del Proyecto, era más restrictiva que la del Grupo Socialista, en cuanto, en la opción socialista, no era descartable cambiar la motivación alegando la violación del mismo precepto constitucional.

25 Vid. Tribunal Constitucional. Trabajos Parlamentarios, op. cit., pág. 136.

26 En el debate de la Comisión se cambia la numeración: el art. 32.2 pasará a ser el art. 29.2 y el art. 42 el 38, y no se producirá en el Pleno ningún debate sobre los artículos, al no ser mantenidas las enmiendas de los Grupos Andalucista, Comunista y Minoría Catalana.

27 Los Senadores de UCD Soriano Benítez, Mendoza y Alvarez Pedreira, propondrían una redacción alternativa más expresiva "fundado en idéntica violación del mismo precepto constitucional», que reducía el ámbito de la prohibición de repetición del recurso, pero que no será aceptada por la Ponencia. 
el Gobierno 28 . El Senador Calatayud Maldonado explicará el cambio, en nombre de la Comisión: "Hemos aceptado el principio evolutivo de la jurisprudencia que ya, en cierta manera, está incorporado en el Título Preliminar del Cc y está reflejado en el art. 29.2 tal y como ha quedado redactado con la corrección de la errata que había, y en el artículo 13. Este principio evolutivo tiene un cauce específico, porque el recurso de inconstitucionalidad no puede ser reproducido, sino que sí puede introducirse por vía de cuestión, promovido por órgano, cuerpo o tribunal prejudicial, por el cauce adecuado en el que se pueda modificar esta jurisprudencia. En todo caso, cuando este hecho se produce, ha de ser sometido necesariamente al pleno del Tribunal. Nunca puede conocer el órgano de menor categoría” ${ }^{29}$.

Independientemente de la excesiva limitación del supuesto de cambio de jurisprudencia a la vía de la nueva cuestión, e incluso, visto el funcionamiento del Tribunal Constitucional, a la del art. 13, lo cierto es que la voluntad de permitir el planteamiento de cuestiones de inconstitucionalidad tras la sentencia desestimatoria del recurso es clara, y su finalidad también precisa: facilitar la evolución del la jurisprudencia. Más claramente aparecerá aún en el mensaje motivado que el Senado enviará al Congreso, donde se afirma que "La adecuación de la jurisprudencia del Tribunal Constitucional a las exigencias de la sociedad ha movido a esta Cámara a enmendar el art. 29.2, suprimiendo la referencia a las razones de forma, con el fin de evitar que un requisito procesal impida a dicho Tribunal Constitucional tener en cuenta datos normativos, sociológicos o históricos de nueva relevancia».

El Congreso de los Diputados se pronunciará sobre las enmiendas introducidas por el Senado en la Sesión del 19 de septiembre de 1979. A la hora de votar la enmienda introducida por la Cámara Alta al artículo 29, y que suprimía la expresión "por razones de forma", el diputado Pons Irazábal en representación del Grupo socialista solicitará que ésta se rechace, fijando en cierto modo el sentido de la votación. Afirmará, utilizando la antigua terminología del Proyecto, que «EI art. 29.2 en su apartado 2, establece el mecanismo de cierre a la impugnación, por vía principal, de una ley o de la promoción de un recurso

28 Curiosamente en el texto oficial del Dictamen de la Comisión se cometerá un error y no se recogerá esta supresión, que será corregida expresamente.

29 Tribunal Constitucional. Trabajos Parlamentarios, op. cit., págs. 470471. 
de inconstitucionalidad, en el supuesto de que haya sido desestimado otro recurso en vía principal. La Comisión y el Pleno establecieron la cautela de que fuese "por razones de forma", y al suprimirse esta cautela queda abierto el cauce para que se reproduzcan indefinidamente recursos por vía incidental, por lo que la experiencia de otros Tribunales Constitucionales aconseja una regulación prudente de esa posibilidad, en la que estuvieron entonces de acuerdo todos los Grupos parlamentarios que en la Ponencia y en la Comisión hicieron su aportación para obtener en esta materia una regulación adecuada» ${ }^{30}$. Tras la explicación del rechazo que se proponía a la enmienda del Senado, la votación fue de $\mathbf{2 7 1}$ a favor de rechazar la enmienda del Senado, 9 a favor de mantenerla y 9 abstenciones. De tal forma, el texto del art. 29.2 conservaría la frase "por razones de forma" que, con la clara finalidad de impedir cuestiones de inconstitucionalidad tras la sentencia desestimatoria de fondo del recurso de inconstitucionalidad, introdujo el Congreso en el texto inicial y mantuvo en el definitivo, a pesar del intento del Senado de suprimirlo pretendiendo posibilitar el planteamiento de posteriores cuestiones de inconstitucionalidad.

\section{EL DEBATE DOCTRINAL EN TORNO A LOS ARTÍCULOS 29.2 Y 38.2 DE LA LOTC}

Serán los primeros trabajos doctrinales aparecidos tras la publicación de la LOTC los que, sin base jurisprudencial alguna en la que apoyarse, fijen sin embargo los términos de un debate que ha permanecido abierto en la literatura jurídica española, en paralelismo con el de los efectos de las sentencias constitucionales, hasta las publicaciones más recientes sobre la jurisdicción constitucional ${ }^{31}$.

Dentro de estas primeras aportaciones existen dos estudios, de Rubio/Aragón y de García de Enterría respectivamente, que ejercerán sin duda una decisiva influencia, no sólo sobre la postura adoptada posteriormente por la doctrina, sino, probablemente, sobre los propios posicionamientos iniciales del Tribunal Constitucional.

30 Tribunal Constitucional. Trabajos Parlamentarios, op. cit., págs. 571 y ss.

31 Así vid., por todas entre las más recientes, GARRORENA, "Artículo 164", en Comentarios a la Constitución de 1978, dir. por O. AlzaGA, t. XII, Madrid, 1999, págs. 336 y ss., o EsPín, "Artículo 29", y GÓMEZ MONTORO, "Artículo 38", ambos en Comentarios a la Ley Orgánica del Tribunal Constitucional, Madrid, 2001, págs. 440 y ss. y 573 y ss. 
En su estudio sobre la jurisdicción constitucional para el libro sobre la Constitución española coordinado por Pedrieri32, Rubio y Aragón someterán a una crítica severa el sistema previsto por los arts. 29.2 y 38.2 LOTC, centrando sus objeciones en el art. 29.2, del cual parecería deducirse según estos autores que la posibilidad de cuestionar la ley tras la sentencia desestimatoria del RI tan sólo sería posible en el caso expresamente contemplado por el artículo, la existencia de una sentencia desestimatoria por razones de forma. Esta modificación «de no menor importancia", unida a la que se realiza en el Proyecto de Ley al atribuir en el art. 38.1 eficacia general a las sentencias de los procedimientos de constitucionalidad, sin especificar el carácter estimatorio o desestimatorio del pronunciamiento, podría conducir al absurdo de una lectura que afirme que las sentencias desestimatorias suponen la imposibilidad de impugnar la norma en el futuro ${ }^{33}$. Semejante consecuencia resultaría incoherente para Rubio y Aragón "con la finalidad característica de la jurisdicción constitucional» en cuanto al impedir la capacidad de la jurisprudencia para "recrear la Constitución", "eliminaría una de las facetas que con mayor fortuna coadyuvan a la permanencia de la Constitución y a evitar excesivas reformas. El ejemplo norteamericano resulta, en este punto, absolutamente esclarecedor ${ }^{34}$.

La oposición frontal de esa interpretación del art. 29 al fin evolutivo de la justicia constitucional hace "que no haya más remedio que

32 "La Jurisdicción Constitucional", op. cit. págs. 829 y ss.

33 Op. cit., pág. 869. Aun cuando los autores ni siquiera mencionan el efecto de cosa juzgada - que por otra parte admiten sin mayores precisiones en el mismo trabajo, y en otros muy próximos en el tiempo-, y sitúen el problema, a nuestro entender correctamente, dentro de "la compatibilidad entre las dos vías de la impugnación" (título de epígrafe, op. cit. pág. 870), parece a primera vista que la identificación de los efectos generales con la imposibilidad de impugnación, presupone la concepción de estos efectos como inmutabilidad de la sentencia frente a todos, y en último término como una cosa juzgada "erga omnes". Cabe destacar por otra parte que en todo caso, y aun aceptando esas consecuencias derivadas del art. 29.2, la imposibilidad de la cuestión sólo se produciría ante la sentencia desestimatoria de un $\mathrm{Rl}$; nada se dice de la posibilidad de plantear una $\mathrm{Cl}$ tras una sentencia desestimatoria de otra cuestión. Por otro lado siempre resultarían abiertas las vías indirectas para lograr un control de constitucionalidad de la ley, la tramitación del conflicto de competencias como control de constitucionalidad de la ley, art. 67, y la llamada "autocuestión" de inconstitucionalidad del art. 55.2, supuestos ambos que permiten siempre el enjuiciamiento de leyes en un tiempo muy posterior al de su promulgación, y sobre el que el art. 29 LOTC no se pronuncia en absoluto.

34 Op. cit., pág. 870. 
realizar una interpretación distinta del precepto", algo que, entendiéndose difícil, se considera «mejor que pedir la derogación o reforma de la ley" ${ }^{35}$.

Es quizá la "peculiaridad" de esta interpretación distinta del art. 29.2 y 38.2 de la $C E^{36}$, la que ha contribuido en parte a la notoriedad de este primer trabajo sobre el tema. Para Rubio y Aragón, el art. 38.2 establece el principio general de compatibilidad de las dos vías, mientras cabe interpretar el art. 29.2 "como una garantía de este último precepto, o mejor dicho, como una garantía absoluta de la compatibilidad entre el recurso y la cuestión de inconstitucionalidad $\${ }^{37}$. Para mantener semejante afirmación los autores, de manera aislada en la doctrina, hasta donde sabemos, identifican la expresión "desestimación por razones de forma" con la desestimación de una impugnación de la ley basada en vicios de inconstitucionalidad formal de esa misma ley. Y así se afirma que si en este supuesto es menos defendible la posibilidad de plantear una cuestión posterior, "para mayor garantía del ciudadano y para evidenciar una interpretación coherente de la libertad del Tribunal Constitucional de revisar su doctrina, la ley ha querido confirmar expresamente que, ni en esos supuestos, se cierra la compatibilidad entre el recurso y la cuestión de inconstitucionalidad ${ }^{38}$. Aun sin prejuzgar la corrección de la finalidad de la interpretación, ni las afirmaciones subyacentes sobre la necesidad de hacer compatible el RI y la $\mathrm{Cl}$, no creemos sinceramente que con una interpretación de este tipo tan sólo "se fuerce un poco la intención del legislador»" ${ }^{39}$.

35 Op. cit., págs. 870-1.

36 Interpretación que por otra parte los autores no recogerán expresamente en ninguno de sus trabajos posteriores.

37 Como argumento para subrayar la imposibilidad de entender el art. 29.2 como limitativo del art. 38.2. se señala su ubicación sistemática fuera del Capítulo IV referido a los efectos de la sentencia constitucional. Con ello, a nuestro entender, los autores incurren en una cierta contradicción, puesto que si el problema del art. 29 y 38 hace referencia a la compatibilidad entre las diferentes vías de impugnación, como los propios autores titulan el epígrafe, parece que su ubicación sistemática dentro del Capitulo I "Disposiciones Generales" es más correcta que dentro de la regulación de los efectos del pronunciamiento. Por otra parte, ciertas expresiones como "de haber querido el legislador tal restricción la hubiera ubicado en el art. 38.2" (op. cit. pág. 871), no dejan de contradecir el sentido real de la voluntad del legislador, voluntad que los propios autores reconocen al mantener la prevalencia en la interpretación de estos preceptos de la "ratio legis" frente a la "ratio legislatoris".

38 Op. cit., págs. 871-2.

39 Op. cit., pág. 872. 
Una postura igualmente crítica con el art. 29.2 de la LOTC se encontrará en García de Enterría. En la primera edición de su Manual tras la aparición de la Ley Orgánica ${ }^{40}$, el insigne administrativista coincide con los anteriores autores en que el juego del art. 29.2 y 38.2 parece asignar un valor "erga omnes" a las sentencias desestimatorias ${ }^{41}$. Para García de Enterría esta interpretación del art. 29.2 y 38.2 supondría gravisimas consecuencias para el ordenamiento jurídico, por toda una serie de razones que completarán las antes expuestas en su trabajo sobre la posición en el ordenamiento jurídico del Tribunal Constitucional de $1981^{42}$. Coincide con Rubio y Aragón en que semejante prohibición de compatibilidad consagraría un riguroso "stare decissis», que obstaculizaría "una de las funciones más importantes del. Tribunal, la interpretación evolutiva ${ }^{43}$. Pero para este autor no sólo se producía la petrificación de la doctrina, sino que además se dotaría a las sentencias de un valor superlegislativo y se equipararía la doctrina del Tribunal Constitucional "a la Constitución misma» 44.

40 Curso de Derecho Administrativo, Madrid, 1983,.op. cit., págs. 171 y ss.

41 Lo que en su opinión descalificaría también, si esa fuera la intención de su confusa redacción, al art. 38.1 del mismo texto.

42 La Constitución como norma y el Tribunal Constitucional, Madrid, 1981, págs. 139 y ss. Hay que señalar que en este trabajo desaparece, como muy bien indica Pérez Tremps, Tribunal Constitucional y Poder Judicial, Madrid, 1985, págs. 261-262, cualquier referencia al valor "erga omnes" que adquirirían, vía art 29.2, las sentencias estimativas. La observación sin embargo pierde importancia dado que Enterría mantiene todos sus argumentos, incluido este último, hasta las ediciones más recientes de su clásico Curso..., vid. así la edición de 1997, págs. 161162. En todo caso, en esta última edición de su manual, ENTERRíA sintetiza sus razones para considerar que la regla del art. 29.2 "carece de todo sentido": la nulidad nunca es convalidable, además, tratándose de un control abstracto de normas, donde no existen verdaderas partes, no puede aplicarse a la sentencia absolutoria la técnica de la cosa juzgada, sino de la interpretación de la ley. La fórmula, por otra parte, consagraría un riguroso principio de "stare decissis" que vincularía al Tribunal a sus propios precedentes y, por último, ese valor absoluto dado a la desestimación "equivale a poner esa sentencia por encima de la Constitución misma, al cerrar el paso a un examen directo y constante de la misman, op. cit., pág. 157.

43 La Constitución como norma jurídica..., op. cit., págs. 139-40.

44 Curso... (1983), op. cit., págs. 153-154. Dejando aparte las observaciones ya realizadas sobre la no exacta equiparación entre prohibición de la cuestión tras un recurso y la imposibilidad absoluta de volver a impugnar la ley, lo cierto es que la doctrina del Tribunal, cualquiera que sea su polémico lugar dentro del sistema de fuentes, no se produce y transforma tan sólo en los procedimientos de control de leyes. En todo caso, en su argumentación es claramente percibible el paralelismo con las críticas que la doctrina italiana realizó inicialmente a una hipotética eficacia general de la sentencia desestimatoria, así vid., entre otros, GAR- 
Por otra parte semejante sistema, "que incide en un error ya superado hace tiempo en el recurso contencioso-administrativo contra reglamentos», del que el art. 29.2 sería una mala copia, es inviable ante la imposibilidad de convalidar la nulidad de pleno derecho de las leyes inconstitucionales ${ }^{45}$. Más interesantes son sus afirmaciones de que tal sistema ignoraría las susceptibles diferencias entre control abstracto y concreto $y$, sobre todo, una afirmación que colocaría por primera vez el tema en relación con la cosa juzgada. Para Enterría, "es imposible aplicar a las sentencias desestimatorias la fuerza de $\mathrm{CJ}$, que no se refiere a situaciones concretas, sino a la interpretación de la ley, materia en la que nunca una sentencia cierra el paso a una posterior interpretación distinta de la misma " ${ }^{46}$. Ni que decir tiene que todas estas aseveraciones llevan al autor a considerar los artículos «manifiestamente inconstitucionales".

Frente a estas afirmaciones, los primeros estudios de la LOTC desde una óptica estrictamente procesal, llegarán a conclusiones sus-

BAGNATI, "Sull efficacia delle decisioni della Corte costituzionale", en Scritti Giuridici in Onore di F. Carnelutti, Padova 1950 págs. 210 y ss.; PIERANDRel, "Le decisioni degli organi della giustizia costituzionale (Natura-eficacia-esecuzione)", en Riv. it. sc. giur., 1954 págs. 190 y ss., o el propio CRISAFULLI, "La Corte costituzionale tra Magistratura e Parlamenton, en Scritti giuridici in memoria di P. Calamandrei, IV, Padova, 1958, págs. 289 y ss. Cabe señalar que toda esta corriente crítica se dirige fundamentalmente contra la idea de que la sentencia desestimatoria sea una especie de interpretación auténtica de la ley, en la línea del primer Calamandrei, más que ante una posible existencia de una cosa juzgada, que en todo caso se considera también inaceptable por entenderse que de existir sería "erga omnes". El debate, por otra parte, no deja de estar condicionado, no sólo por la ausencia de cualquier referencia normativa expresa, sino también por la casi exclusividad práctica de la cuestión de inconstitucionalidad en el sistema italiano. No nos encontramos, pues, ante un debate de compatibilidad de vías, sino ante el de la reproposición de cuestiones.

45 La Constitución como norma jurídica..., op. cit., pág. 136. Argumento que, como señala AHUMADA RUIz, "Sobre la cosa juzgada" (ejemplar mecanografiado), cit. por Corzo Soso, La Cuestión de Inconstitucionalidad, Madrid, 1998, pág. 532 , no deja de ser reversible en el caso de una ley posteriormente declarada inconstitucional tras una sentencia desestimatoria, y al que es aplicable también en paralelo lógico la típica discusión doctrinal sobre la sentencia injusta y la cosa juzgada. En esta línea vid. las contraargumentaciones de RUGGIERI, Storia di un "falson..., op. cit., págs. 41 y ss.

46 Curso... (ed. 1997), op. cit., pág. 157. Otras afirmaciones anteriores como que la inexistencia de una legitimidad individual en la impugnación de las leyes vendría a privar a los ciudadanos de garantías consagradas en el art. $24 \mathrm{CE}$, pensamos que hoy son matizables a la luz del funcionamiento real del recurso de amparo "contra leyes" y de las afirmaciones de la jurisprudencia constitucional sobre la denegación por parte del juez "a quo» del planteamiento de la $\mathrm{Cl}$. 
tancialmente distintas. En esta línea doctrinal serán fundamentales los trabajos de Almagro Nosete y González Pérez sobre la Ley Orgánica del Tribunal47. Estos autores mantienen que el art. 38.1 consagra una eficacia "erga omnes" para todo tipo de sentencias, y por tanto también para las sentencias desestimatorias, que se plasma en este último caso en la existencia de una cosa juzgada "erga omnes", sin límite subjetivo alguno, bien por mandato legal, bien por las características propias del sistema concentrado de control constitucionalidad.

Este planteamiento inicial les lleva a explicar el art. 29.2 y 38.2 dentro del efecto de la cosa juzgada. Para Almagro el art. 29 se refiere a las sentencias desestimatorias por un vicio formal en el planteamiento del recurso y no por un vicio de inconstitucionalidad formal de la ley, como se sostenía por Rubio y Aragón, y esta es una previsión que debe extenderse también a las sentencias desestimatorias por razones de forma de las cuestiones de inconstitucionalidad. Lo único que vendría a consagrar el art. 29.2 sería pues la imposibilidad "de un nuevo proceso donde se repitan las causas obstativas de naturaleza procesal» que impidieron entrar la primera vez en el fondo del problema de constitucionalidad. Los pronunciamientos constitucionales en estos casos tendrán por tanto una eficacia de cosa juzgada reducida a impedir esta repetición de la causa obstativa, lo que les priva en cierto modo del "iudicato" "erga omnes" predicable de las sentencias desestimatorias sobre el fondo del asunto.

Bajo esta nueva perspectiva, el art. 29.2 es perfectamente explicable en términos procesales y en absoluto contradice el art. 38.2 LOTC. Este último artículo se limita a plasmar el efecto impeditivo de la sentencias desestimatorias del recurso de inconstitucionalidad frente a un recurso posterior, efecto derivado de la eficacia de cosa juzgada «erga omnes" de la sentencias desestimatorias de fondo y por tanto predicable, por mucho que la LOTC no lo diga y el art. 38.2 parezca indicar lo contrario, de la sucesión entre cuestiones de inconstitucionalidad. En ambos casos la repetición de un juicio idéntico tras la sentencia desestimatoria supondría menoscabar la cosa juzgada uerga omnes" de las sentencias (sus efectos generales, para este grupo de autores).

47 Almagro Nosete, Justicia Constitucional (Comentarios a la LOTC), Madrid, 1980, y sin modificaciones para nuestro tema, la edición de 1989 con SAAVEdRa Gallo, cuyas posiciones serán confirmadas por la obra de González PÉrez, Derecho procesal constitucional, op. cit., del mismo año. También será ésta la postura posteriormente seguida en la obra de los constitucionalistas DE ESTÉBAN Y GoNzÁlez Trevijano, Curso de Derecho Constitucional español, Madrid, 1992, y 1994. 
Ahora bien, la precisión final del art. 38.2 «fundado en infracción de idéntico precepto constitucional", vendría a remarcar algo obvio desde el punto de vista procesal: la cosa juzgada sin límites subjetivos sí los tiene en cambio objetivos, y el efecto obstativo de la sentencia desestimatoria de la $\mathrm{Cl}$ o el RI no se producirá ante un cambio en la "causa petendi". Para estos autores no se trata por tanto de un problema de compatibilidad entre las vías, que por otra parte su concopción del uiudicato" sin límites subjetivos difumina, sino de la aplicición de los efectos de la cosa juzgada "erga omnes", que el art. 38.1 rorisagra, a los distintos supuestos procesales ${ }^{48}$.

Durante estos primeros años, y sin más pronunciamiento jurispr'.dencial que la STC 4/81 sobre la preconstitucional Ley de Régimen Loc:al, donde como veremos parecía abrirse, aunque sutilmente, la posibilidad de plantear nuevas cuestiones tras la sentencia desestimatoria de un recurso de inconstitucionalidad, merece destacarse también la existencia de una línea de opinión más moderada que la representada en sus "extremos" por Enterría/Rubio y Almagro, y que tiende a buscar interpretaciones menos forzadas de la ley. Próxima a las posturas críticas es la posición de Arozamena ${ }^{49}$. Para el autor, el art. 29.2 se hace difícilmente conciliable con el art. 38.2, y "ofrece técnicamente puntos vulnerables». Sin pronunciarse sobre una interpretación concreta, salvo la de que el art. 29.2 se refiere a la desestimación de la impugnación por razones de forma y no por vicios formales de la ley, reflexiona sobre la necesidad de no trasladar mecánicamente conceptos procesales civiles al proceso constitucional sin tener en cuenta la diferencia sustancial entre "dictum civil" y el "dictum de la jurisdicción constitucional»50, y propugna la búsqueda de una interpretación que optimice los fines del proceso sobre la función

48 Almagro, op. cit. pág. 171; González Pérez, op. cit., págs. 260 y ss., y del mismo autor "La cuestión prejudicial de inconstitucionalidad", en El Tribunal Constitucional, II, op. cit., págs. 1237-8 o de Saavedra Gallo, La duda de inconstitucionalidad, Córdoba, 1985, pág. 279. Ésta es la línea que seguiría también sustancialmente PASTOR RIDRUEJo, "Aplicación de la ley y control de constitucionalidad", op. cit. págs. 2023 y ss., el único autor que realiza una defensa explícita del sistema consagrado en la LOTC, y muy posteriormente, con un ambiente doctrinal no proclive a esta interpretación, GARCía Couso, El juicio de relevancia en la Cuestión de Incostitucionalidad, Madrid, 1998, págs. 163-165.

49 Quien; como es sabido, fue, junto con RuBIo LLORENTE, uno de los autores del Proyecto y uno de los primeros magistrados del Tribunal Constitucional. Sus reflexiones se encuentran en "El Recurso de Inconstitucionalidad", en El Tribunal Constitucional, V. II, Madrid, 1981, págs. 173 y ss.

50 Op. cit., pág. 175. 
preclusiva de la cosa juzgada, no impidiendo así la evolución de la jurisprudencia 51 .

Más cercano en cierto modo a las posiciones de Almagro o González Pérez parece López Guerra en su trabajo de $1981^{52}$. En la búsqueda también de "una interpretación menos extrema que la de inconstitucionalidad" de los art. 29.2 y 38.2 de la LOTC, destaca que el art. 38.2 tiene como límite de su efecto impeditivo de nuevos recursos directos "la infracción de un precepto idéntico". Esto le lleva a resaltar la importancia de la motivación en la búsqueda del alcance efectivo de lo decidido por el Tribunal Constitucional, y a propugnar por tanto que el art. 38.2 "impedirá una cuestión sobre puntos ya resueltos y mencionados en la motivación de la sentencian y no sobre "hechos nuevos". En paralelo mantiene que la posibilidad de una nueva cuestión de inconstitucionalidad tras una sentencia desestimatoria de una primera cuestión dependerá de la existencia de una nueva duda, en cuanto referida a otra interpretación del precepto legal o del artículo constitucional, ya que, "si la cuestión es una pregunta concreta, la sentencia es siempre una respuesta concreta"s ${ }^{53}$. López Guerra llega pues a resultados parecidos a los procesalistas mencionados, pero con la importante salvedad de no pronunciarse en absoluto, y sin necesidad de compartir, los supuestos teóricos particulares de los que estos parten: la eficacia general de las sentencias desestimatorias y la consiguiente $\mathrm{CJ}$ "erga omnes" de la sentencia constitucional.

Dentro de esta "línea media» de la doctrina puede situarse también un importante y no muy conocido trabajo de Elizalde ${ }^{54}$, quien compartiendo que el art. 29.2 se refiere a la sentencia desestimatoria por defecto formal de la impugnación, claramente mantiene que respecto a este tipo de pronunciamiento puede directamente afirmase la falta de cosa juzgada. Para la sentencia desestimatoria de los recursos de inconstitucionalidad se establecerá un efecto de cosa juzgada, pero con un nuevo límite, que el proceso se inicie por la misma vía de

51 Op. cit., págs. 174-175. En todo el artículo, AROZAMENA parece claramente optar por una interpretación que posibilite la compatibilidad de las vías de impugnación y la reproponibilidad de las cuestiones de inconstitucionalidad, sin embargo una exquisita prudencia doctrinal, explicable desde su condición de magistrado, parece impedirle optar por una solución explícita.

52 "EL Tribunal Constitucional y el principio del "stare decisis" ", en El Tribunal Constitucional, v. II, Madrid, 1981, págs. 1473 y ss.

53 Op. cit., pág. 1451.

54 «El Tribunal Constitucional y la jurisprudencia», op. cit. págs. 863 y ss. 
impugnación ${ }^{55}$, lo que viene a significar el posible replanteamiento de cuestiones sucesivas e idénticas al tema resuelto en el recurso de inconstitucionalidad. Las sentencias desestimatorias de fondo de la cuestión de inconstitucionalidad, producirán tan sólo una cosa juzgada "para el juez y las partes del proceso a quo", lo que permitiría, en el seno de otros procesos, el replanteamiento sin grandes limitaciones de cuestiones sucesivas en el tiempo ${ }^{56}$. Es Elizalde por tanto, quien más ampliamente propugna la "replanteabilidad" de los problemas de constitucionalidad ante el Tribunal Constitucional, aceptando no sólo la posibilidad de la sucesión entre el $\mathrm{RI}$ y la $\mathrm{Cl}$, sino entre las cuestiones sustancialmente idénticas ${ }^{57}$.

La sugerencia de que la compatibilidad entre el recurso y la cuestión, ex artículo 38.2 LOTC, iba a suponer un límite particular añadido a los tradicionales límites de la cosa juzgada, para el supuesto de la sentencia sobre la ley, será retomada mucho más recientemente por Garrorena, en su clarificador estudio sobre el art.164 de la Constitu-

55 Op. cit., pág. 878.

56 Op. cit., págs. 878-79.

57 Como veremos esta será la postura que, fundamentalmente a partir de JIMÉNEZ CAMPO, vid., "Los procedimientos de declaración de inconstitucionalidad", en Los procesos constitucionales, Madrid, 1992, pág. 21; "Consideraciones sobre el control de constitucionalidad de la ley en el derecho espańol», en La Jurisdicción Constitucional en España (LOTC: 1979-1994), Madrid, 1995, págs. 103-105, y "Qué hacer con la ley inconstitucional", en La sentencia sobre la constitucionali: dad de la ley. Madrid, 1997, págs. 27-28, se va a ir convirtiendo en dominante en la doctrina española, especialmente en esta última etapa, y como efecto también de la interpretación de determinadas líneas jurisprudenciales del Tribunal Constitucional. Así, PUNSET, «Canon, carácter vinculante, contenido y efectos de los pronunciamientos sobre la constitucionalidad de las leyes", en La sentencia sobre la constitucionalidad de la ley, op. cit. págs. 84-85; Ignacio DíEz-PICAZO, "Reflexiones sobre el contenido y efectos de las sentencias dictadas por el Tribunal Constitucional en recursos de amparo", en La sentencia de amparo constitucional. Madrid, 1996, pág. 64; Manuel MEDINA, "Los procedimientos de control de constitucionalidad de las leyes. El control indirecto. Las sentencias en los procedimientos de control», en Jurisdicción y procesos constitucionales, Madrid,1997. pág. 69, y Corzo SosA, La cuestión de inconstitucionalidad, op. cit. págs. 522-3, entre otros. Lo que diferencia a Elizalde de esta corriente será el intento previo de una delimitación de la cosa juzgada como base explicativa del fenómeno de la compatibilidad. Una posición singular, sumamente interesante, y que intenta conjugar cosa juzgada y evolución jurisprudencial en base a una rigurosa delimitación conceptual del efecto previsto por el art. 164 de la constitución, puede verse apuntada en los trabajos de AHUMADA RUIZ, "Sobre la cosa juzgada",op. cit., "El control de constitucionalidad de las omisiones legislativas", en R.C.E.C., 1991, o "La regla de la mayoría y la formulación de la doctrina constitucionalı, R.E.D.C., 2000. 
ción ${ }^{58}$. Para este autor, el efecto de cosa juzgada de las sentencias constitucionales se funda en su finalidad de impedir la reiteración o sucesión de procesos idénticos. Sin embargo es en el control de leyes donde este instituto sufrirá "una modificación bastante profunda de las condiciones que lo definen en el derecho procesal común". En las sentencias desestimatorias, la justificación del efecto es sin embargo evidente, "la reiteración de procesos por el juez de constitucionalidad debe tener un freno, y ese freno, en puro respeto a las categorías ya acuñadas, no puede ser otro que la cosa juzgada materialı59.

Ahora bien, para Garrorena la cosa juzgada carece aquí de límites subjetivos, en cuanto se deriva directamente de los destinatarios de la sentencia y de manera indirecta del carácter general de la norma enjuiciada ${ }^{60}$. Con ello se renuncia al juego de estos límites para garantizar la evolución de la jurisprudencia constitucional, puesto que la cosa juzgada vinculará al "juez a quo", a las partes procesales y al propio Tribunal Constitucional ${ }^{61 .}$

Persistirá sin embargo el límite objetivo - que los términos del problema sean idénticos-y un límite específico, ya que debido a la expresa regulación legal de las relaciones entre el recurso y la cuestión de inconstitucionalidad, se producirá una "retracción lógica del instituto de la cosa juzgada» ${ }^{62}$.

Garrorena realiza pues una interpretación "clásica» del juego de los artículos 29.2 y 38.2 de la LOTC para llegar a la conclusión de que el sistema de impugnación se basa en una compatibilidad sustancial entre recurso y cuestión. Compatibilidad que encuentra su razón de ser constitucional en la finalidad propia de la cuestión: convertirse en una vía abierta a las exigencias que se derivan de la aplicación concreta del derecho ${ }^{63}$.

Semejante interpretación no convertiría en incompatible a la cosa juzgada con la regulación de la LOTC, sino que simplemente modifica por vía normativa el régimen general del instituto. No existe sin embargo ningún precepto legal que justifique la exclusión de la 
cosa juzgada en los casos de repetición de acceso por la misma vía, y por tanto en estos supuestos, el planteamiento de una idéntica duda constitucional, dada la ausencia de límites subjetivos de la cosa juzgada, implicaría la imposibilidad para el Tribunal Constitucional de entrar a conocer el fondo del asunto. El reconocimiento de una limitación por vía legal al normal efecto de la cosa juzgada permite así al autor garantizar el dinamismo del sistema sin renunciar a una "res iudicata" "erga omnes".

Particulares y aisladas en cierto modo dentro de la doctrina serán las posiciones de Bocanegra ${ }^{64}$, y Pérez Tremps ${ }^{65}$. Bocanegra, que considerará a la cosa juzgada como eje del sistema de efectos de la sentencia constitucional, comparte sin embargo con Enterría el especial tono crítico hacia la regulación de los arts. 29.2 y 38.2 LOTC 66.

Para este administrativista, autor de una importante monografía sobre los efectos de los pronunciamientos constitucionales ${ }^{67}$, las sentencias desestimatorias, a pesar de la posible interpretación del art. 38.1. y de los artículos estudiados de la LOTC, carecen por completo de efectos generales. No obstante, la posible revisión de las sentencias desestimatorias de los recursos o cuestiones de inconstitucionalidad dependerá no de los arts. 29.2 y 38.2 de la LOTC, sino de la aplicación de los límites del efecto de cosa juzgada de este tipo de sentencias, que el autor singulariza en la "norma concreta de la decisión" para el aspecto objetivo, y en los posibles participantes en el proceso ante el Tribunal Constitucional en su vertiente subjetiva. Del hecho de que los ciudadanos no se encuentren afectados por los límites subjetivos de la "res iudicata», deducirá el autor la permanente posibilidad de replantear sucesivas cuestiones de inconstitucionalidad tras una primera sentencia desestimatoria de cualquier tipo ${ }^{68}$.

64 El valor de las sentencias del Tribunal Constitucional, Madrid, 1982.

65 Tribunal Constitucional y Poder Judicial, Madrid, 1985.

66 "Definitiva y claramente inconstitucional" porque "inadmisible, completamente inconstitucional e incoherente en su concreta regulación con la economía de la propia LOTC", págs.257-258, son algunas de sus afirmaciones sobre una regulación que, para el autor, el art. 29.2 establece y el art. 38.2 «repite aún con más claridad".

67 La única existente, hasta donde sabemos, en la doctrina española, sobre el efecto de las sentencias constitucionales en general.

68 Más peculiaridades presenta la posibilidad teórica de un RI tras una sentencia desestimatoria de otro RI, en cuanto aquí el único posible no afectado por la cosa juzgada, y dentro siempre de la peculiar interpretación sobre la legitimación de las CC.AA. que contempla el autor, peculiar al menos para la época, es el 
Pérez Tremps, en su obra Tribunal Constitucional y Poder Judicial ${ }^{69}$, intentará una nueva interpretación del art. 29.2 que permita una relectura conforme a la mencionada STC 4/81, y que salve al precepto de consagrar una autovinculación del Tribunal a su doctrina. Para el autor el art. 29.2 «quizás pudiera tener un sentido procesal permitiendo al Tribunal Constitucional rechazar cuestiones de inconstitucionalidad similares y sobre el mismo objeto acerca del que se decidió en el recurso, por auto y no por sentencia, siempre que existan esas identidades y mucha cercanía en el tiempo "70. Salvada así la compatibilidad entre el art. 38.2 y el art. 29.2, el autor mantendrá que las sentencias desestimatorias poseen no obstante efectos generales, pero no en el sentido de una cosa juzgada "erga omnes", sino en el de que también vinculan a los poderes públicos ${ }^{71}$.

Tras estos primeros estudios sobre la jurisdicción constitucional, el tema de la compatibilidad entre las vías de acceso entra en cierta manera en un periodo de pacífico consenso, donde una gran parte de la doctrina se limita a constatar la aceptación por el TC de la posible compatibilidad entre recurso y cuestión en la sentencia $4 / 81$ y a recoger más o menos sumariamente la posible contradicción entre el art.

Defensor del Pueblo y ello siempre que no participara en el primer proceso, op. cit., págs. 262 y ss.

69 Op. cit., págs. 260 y ss.

70 Op. cit., pág. 261.

71 Vid. también García MARTínez, El recurso de inconstitucionalidad, Madrid, 1992, págs. 225 y ss. Dentro de las interpretaciones "peculiares» de estos artículos merece destacarse la que GaRcíA TORRES, en La Jurisdicción Constitucional en España..., op. cit. (aportación al debate oral), págs. 120-121, realiza del art. 38.2 , al proponer entender que en la frase uimpedirá cualquier planteamiento ulterior de la cuestión por la misma vían, el planteamiento ulterior de la cuestión haría referencia a la cuestión de inconstitucionalidad, y el "por la misma vía" a la vía declarativa de inconstitucionalidad. De esta forma el art. 38.2 estaría realmente cerrando la posibilidad de plantear otras $\mathrm{Cl}$ con igual alegación del parámetro de constitucionalidad. La interpretación, que contradice expresamente la interpretación que el TC realiza del art. 38.2, choca también con la interpretación histórica de la elaboración de la LOTC, donde queda claro que el planteamiento de la cuestión "por la misma vía" se refiere a la vía principal, en oposición a la vía incidental, términos que en un primer momento designaban a los posteriores recurso $y$ cuestión de inconstitucionalidad. Hoy en día, tras la modificación de la dicción del art 38.2, al incluir los conflictos en defensa de la autonomía local, la explicación de García Torres encuentra un mayor obstáculo, en cuanto al prohibir cualquier planteamiento ulterior de la cuestión "por cualquiera de las dos vías", parece ya claro, como señalamos, que el término "vías" se refiere al recurso de inconstitucionallidad y al conflicto sobre la autonomía local. 
29.2 y el 38.2, y las críticas que a la literalidad del primero realizan autores como Rubio o Enterría72.

Una postura singular será sin embargo la mantenida por Marín Pageo en su sólida obra sobre la cuestión de inconstitucionalidad en el proceso civil $^{73}$. La singularidad deriva no tanto de la crítica hacia una posible consagración por el art. 29.2 de los efectos generales de la sentencia desestimatoria, ya insinuados en la ambigua redacción del art. 38.1 LOTC $^{74}$, sino de que, llevando al final la intuición de Enterría sobre la inutilidad de la aplicación del concepto de cosa juzgada para explicár las sentencias desestimatorias, termina infiriendo de la compatibilidad entre las distintas vías de acceso el principio general de la inexistencia de un efecto de cosa juzgada en las sentencias desestimatorias de la cuestión de inconstitucionalidad. El art. 38.2 LOTC, al prohibir únicamente la sustanciación de un nuevo recurso de inconstitucionalidad, tan sólo estableceria este efecto para el supuesto de la sentencia desestimatoria del recurso y no para la de la cuestión.

Con ello comenzará una nueva línea crítica en torno a la posible inexistencia del efecto de cosa juzgada en el pronunciamiento, una postura que la también procesalista Blasco Soto, en su estudio sobre los efectos de la sentencia de la cuestión de inconstitucionalidad, extenderá a todas las sentencias desestimatorias del Tribunal Constitucional, sean estas producto de un recurso o de una cuestión ${ }^{75}$. Es así,

72 Así una línea de trabajos que pasa por Fernández Segado, La Jurisdicción Constitucional en España, Madrid, 1984, págs. 117-118; CANo Mata, Comentarios a la LOTC, Madrid, 1986, págs. 135 y ss.; MONTORO PuERTO, Jurisdicción Constitucional y procesos constitucionales, t. l, Madrid, 1991, págs. 225 y ss., o CaAmaño DOMínguEZ, "Los procesos de control directo", en Jurisdicción y procesos constitucionales, op. cit., págs. 69 y ss., entre otros muchos.

73 La cuestión de inconstitucionalidad en el proceso civil, Madrid, 1990.

74 Op. cit., págs. 312 y ss. La autora identifica en el fondo estos efectós generales con la $\mathrm{CJ}$ "erga omnes" y coincidiendo por tanto en el fondo con la postura de Enterría, no resulta extraño que su verdadero "catálogo" de objeciones coincida también, extremando algo el planteamiento, con el de Enterría diez años antes. Una postura similar ya en PIBERNAT DOMÉNECH, "La sentencia constitucional como fuente del derecho", R.D.P., 1987, pág. 62.

75 "Reflexiones sobre la cosa juzgada en las sentencias de las cuestiones de inconstitucionalidad", en R.E.D.C., 1994, págs. 32 y ss. Mucho más elípticamente en La sentencia en la cuestión de inconstitucionalidad, Barcelona, 1995, fruto ambos trabajos de su tesis doctoral. La autora matiza que en las sentencias desestimatorias interpretativas sí puede producirse un efecto positivo de cosa juzgada para el propio TC. El planteamiento de ambas procesalistas, implica pues, la negación de un "iudicato» que ellas presuponen "erga omnes», en cuanto de otra con- 
como, por último, en uno de sus más recientes trabajos sobre la jurisdicción constitucional, Rubio Llorente señalará que «la naturaleza propia de la jurisdicción constitucional lleva inevitablemente a la conclusión, coincidente con la práctica del Tribunal Constitucional, de que las sentencias desestimatorias carecen de la eficacia propia de la cosa juzgada, en cuanto no impiden el planteamiento de nuevas cuestiones frente a los mismos preceptos constitucionales". Y ello porque de lo contrario "la doctrina fijada en un momento determinado quedaría petrificada y se haría imposible una evolución que adecuara la interpretación de la Constitución a la realidad social del tiempo en que ha de ser aplicada, para utilizar la expresión consagrada por nuestro Código Civil»76.

Como ya apuntamos anteriormente, la postura actualmente dominante en la literatura sobre el tema es la de entender que el art. 38.2 permite claramente al Tribunal conocer sobre una cuestión de inconstitucionalidad tras una sentencia desestimatoria del recurso de inconstitucionalidad, pretiriendo intencionadamente al art. 29.2 LOTC. Se afirma también la compatibilidad entre cuestiones de inconstitucionalidad sucesivas y se evita cualquier planteamiento detallado de la relación entre los efectos de la cosa juzgada, con lo que ello implica de definición de sus límites, y los artículos legales estudiados.

Una postura que, en cierto modo, sintetiza y profundiza a su vez esta línea doctrinal, es la mantenida por Jiménez Campo en sus últi-

cepción de la institución, por ejemplo de una cosa juzgada limitada subjetivamente, no podría predicarse su inexistencia por el mero hecho de la compatibilidad entre las vías de acceso. Otra postura particular será la que mantiene GOMEZ Montoro, "Los efectos de las sentencias del Tribunal Constitucional", en Jurisdicción y procesos constitucionales, op. cit., y antes, referido al conflicto de atribuciones, en El conflicto entre órganos constitucionales, Madrid, 1992, págs. 450 y ss., donde, sin mencionar a lós artículos de la LOTC estudiados, deduce que en las reproposiciones de dudas constitucionales, el Tribunal en general puede de hecho "disponer" del efecto de cosa juzgada, entrando a conocer o no del problema constitucional según lo estime conveniente. Una crítica puntual a esta idea en GarrorenA, "Art. 164", Comentarios...op. cit., pág. 345. Gómez Montoro matiza en cierta medida su postura en "Art. 38", Comentarios a la Ley..., op. cit., pág. 564, afirmando básicamente que en todo caso el efecto positivo de la cosa juzgada debe forzar al juez constitucional a fundamentar su cambio de opinión, que en la mayoría de las ocasiones será debido a la modificación real del objeto del juicio.

76 "La jurisdicción constitucional en España", en Estudios sobre la jurisdicción constitucional, op. cit., págs. 11-12. 
mos trabajos sobre la jurisdicción constitucional77. De entre ellos, cabe destacar la interpretación que este constitucionalista, buen conocedor del funcionamiento real del Tribunal, da al art. 38.2 en su aportación a la obra colectiva La Jurisdicción Constitucional en España (La Ley Orgánica del Tribunal Constitucional: 1979-1994) ${ }^{78}$. En ella no sólo reafirma el "sentido permisivo o de apertura" del art. 38.2 LOTC, al permitir implícitamente su texto el planteamiento de una cuestión tras la sentencia desestimatoria del recurso de inconstitucionalidad, sino un posible sentido "impeditivo o de cierre" del mismo, que correspondería a su sentido literal: la imposibilidad de plantear un recurso de inconstitucionalidad tras una sentencia desestimatoria de otro inicial recurso, y que haría, en su interpretación, este sentido literal menos fútil dados los plazos actuales de resolución de los recursos por el Tribunal. Para Jiménez Campo, el art. 38.2 serviría para impedir, por el efecto obstativo de la cosa juzgada, la presentación de recursos, basados evidentemente en la infracción de idéntico precepto constitucional, pero contra una disposición que reproduzca exactamente la "norma" declarada no inconstitucional por el TC en la primera sentencia desestimatoria. Con ello, según el autór, se cumpliría el "fin político" del RI, el cierre de la permanente disputa politica sobre la legitimidad constitucional de la ley, y se impediría además, en el caso de tratarse realmente de un "conflicto de competencias legislativo", que el Tribunal Constitucional tuviera que suspender automáticamente una norma idéntica a la ya anteriormente declarada no contraria a la Constitución ${ }^{79}$.

77 En sus aportaciones, ya citadas, a las obras colectivas Los procesos constitucionales, 1991; La Jurisdicción Constitucional en España, 1995; Jurisdicción Ordinaria y Tribunal Constitucional, 1996; La sentencia sobre la constitucionalidad de la Ley, 1997, o su voz "Sentencia del Tribunal Constitucional", en Temas básicos del Derecho Constitucional, III. 2001.

78 "Consideraciones sobre el control de constitucionalidad de la ley en el derecho español", op. cit., págs. 103-104, interpretación que reiterará en sus trabajos posteriores y que acogerán expresamente MEDINA GuerRero, op. cit.; Corzo SOSA, op. cit., y Gómez MONTORo, "Art. 38", en Comentarios a la Ley..., op. cit.

79 Op. cit., pág. 104, donde cita una serie de sentencias del TC que, según el autor, constítuyen "atisbos" de la adopción de este sentido obstativo por parte del Tribunal. Independientemente de las concretas críticas que pudieran hacerse a esta interpretación, el posible uso por parte del TC de esta posibilidad debería estar condicionado por la valoración del elemento temporal de la repetición, porque tan sólo una repetición muy próxima de la norma, junto con una impugnación también cercana da la misma, permitirían que con esta medida se pusiera realmente fin a un "debate político" real. 
La doctrina ha pasado pues, a lo largo de estos casi veinte años de literatura jurídica sobre el tema, de denunciar la tacha de inconstitucionalidad de los artículos 29.2 y 38.2, buscar interpretaciones realmente forzadas de las mismas o aceptar implícitamente su contenido "potencial» intentando su explicación a través del fenómeno de la cosa juzgada, a resolver el problema de la compatibilidad en una "comunis opinion favorable a la misma, entendida por otra parte en su sentido más amplio ${ }^{80}$. En este camino, la progresiva lejanía temporal de la inequívoca voluntad del legislador orgánico y, sobre todo, la ayuda, aunque matizada y no especialmente abundante, como veremos, de la interpretación que del art. 38.2 ha realizado el TC, han contribuido a provocar un verdadero "desueto" del art. 29.2, que reducido a su simple tenor literal, no pasa de ser una manifestación no especialmente eficaz de la falta de efecto de la cosa de cualquier resolución del Tribunal Constitucional que no verse sobre el fondo del asunto ${ }^{81}$.

\section{LA JURISPRUDENCIA DEL TRIBUNAL CONSTITUCIONAL SOBRE EL ARTÍCULO 38.2 DE LA LOTC}

Como ya señalamos anteriormente, la labor de interpretación del Alto Tribunal sobre los artículos objeto de nuestro estudio destaca por el escaso número de resoluciones en que tal tema es abordado de manera central, en contra de lo que una primera impresión sobre el funcionamiento posible del sistema de control de constitucionalidad pudiera hacer pensar. Por otra parte, y hasta donde sabemos, el Tribunal Constitucional ha eludido sistemáticamente realizar cualquier pronunciamiento significativo sobre el art. 29.2, cuya interpretación por

80 No sólo la compatibilidad entre el recurso y la cuestión de inconstitucionalidad, sino entre sucesivas cuestiones o entre disposiciones idénticas de recursos consecutivos. Esta línea expansiva es perceptible en los intentos de algún autor, como Mieres Mieres, El incidente de constitucionalidad en los procesos constitucionales, Madrid, 1998, págs. 178-179, de aplicar el artículo 38.2 en sentido analógico para inadmitir dos recursos de amparo fundados en la inconstitucionalidad de la misma ley analizada en un primer recurso de amparo "contra ley".

81 Es este punto de llegada el que permite a M. ARAGón, “La aplicación judicial de la Constitución: algunas consideraciones sobre la Justicia Constitucionaln, en Estudios de Derecho Constitucional. Madrid, 1998, pág. 119, afirmar la existencia de una compatibilidad entre recurso y cuestión de inconstitucionalidad uque con dudosa redacción, pero con correcta interpretación por el propio Tribunal Constitucional, establecen los artículos 29.2 y 38.2 ". 
tanto debe entenderse implícitamente realizada por contraste con la que se emite sobre el artículo 38.2 LOTC. El hecho cierto de que el TC haya salvado la posible antinomia entre los contenidos "deducibles" de ambos artículos reforzando el que se deriva implícitamente de la redacción del art. 38.2 no puede ser ajeno a este "silencio" del Tribunal sobre el polémico art. 29.2, objeto preferente de críticas por parte de la doctrina.

Parece evidente también que el órgano constitucional ha optado por no realizar una interpretación explícita del art. 29.2, que, a la luz de su doctrina sobre el art. 38.2, forzosamente habría de ser abiertamente contraria a la declarada intención del legislador orgánico. Razones de prudencia institucional le llevan a evitar un enfrentamiento directo con el legislador en producto normativo tan sumamente particular para el funcionamiento de la jurisdicción constitucional como es su propia ley orgánica, a la que expresamente el Tribunal Constitucional se encuentra sometido por el artículo 1.1 de la LOTC. No puede obviarse, sin embargo, que nos encontramos aquí ante un caso claro de, al menos, "modulación interpretativa" por parte del TC de sus propias normas procesales de funcionamiento y ejemplo claro del importantísimo papel que juegan los propios tribunales constitucionales en la concreción práctica del llamado derecho procesal constitucional. El hecho de que el Tribunal adoptara una postura funcionalmente eficaz y respaldada ya por una gran mayoría de la doctrina ha hecho que, en el seno de ésta, esa libertad configurativa no haya recibido ninguna observación crítica.

El Alto Tribunal va sin embargo a pronunciarse sobre el artículo 38.2 en una de sus primeras resoluciones. Será con ocasión del recurso de inconstitucionalidad presentado contra determinados artículos de la Ley de Bases de Régimen Local de 1945 (STC 4/81, de 2 de febrero ${ }^{82}$. Es decir, con ocasión del control de una normativa preconstitucional, donde el TC, además de sentar su importante doctrina sobre el papel de los jueces ordinarios y de él mismo en el control de las leyes preconstitucionales, establecerá por primera vez una interpretación del art. 38.2 tendente a ratificar lo que implícitamente parecía derivarse del mismo: la compatibilidad entre la sentencia desestimatoria del RI y la posible promoción del cuestiones de inconstitucionalidad futuras. Así

82 Donde se impugnaron también otra serie de artículos de la Ley de Sanidad Nacional, 1944, Ley de Montes de 1977 y Ley de Bases del Estatuto de Régimen Local. El TC emitirá una sentencia estimativa parcial, con pronunciamientos de derogación y otros de interpretación. 
afirmará en el FJ 15: "Mientras tanto, si en el futuro se plantearan casos concretos que permitieran apreciar nuevos matices en orden a justificar la oposición - o la disconformidad - a la CE de alguno de los preceptos cuya inconstitucionalidad no se declara ahora, el juez o tribunal correspondiente podría proponer la cuestión de inconstitucionalidad con relación al precepto que le suscitara la duda, de acuerdo con lo dispuesto en el art. 38.2 de la LOTC".

Sobre este "obiter dicta", que tendrá una influencia decisiva en la doctrina, en cuanto ésta entenderá explícitamente consagrada la compatibilidad entre $\mathrm{Rl}$ y $\mathrm{Cl}$ e implícitamente rechazada la argumentación deducible del art. 29.2, cabe realizar, sin embargo, una serie de precisiones. En primer lugar, la peculiaridad de la situación legal objeto de control. Lo cierto es que el Tribunal Constitucional da a entender que no sólo los artículos objeto de impugnación en el recurso son disconformes con la Constitución, sino que, obviamente, todo el sistema de régimen local responde a unos principios ajenos al marco constitucional, por lo que el propio Tribunal realiza la que puede considerarse la primera "apelación" al legislador en una de sus sentencias, a fin de que adecue la normativa al nuevo sistema ${ }^{83}$.

Es aquí donde la posibilidad de planteamiento de nuevas cuestiones de inconstitucionalidad por parte de los órganos judiciales se convierte realmente en casi una invitación del TC a la colaboración de los jueces ordinarios en la depuración del ordenamiento preconstitucional durante la situación de inactividad del legislador. Por otra parte esta era una buena ocasión para reconocer la necesidad de que los pronunciamientos sobre el recurso de inconstitucionalidad no "blindaran" definitivamente a la ley frente a las múltiples dudas constitucionales que tal normativa ha suscitado, dudas no analizadas en su totalidad en virtud del principio de congruencia procesal de la sentencia. No puede olvidarse tampoco que tratándose de una normativa preconstitucional, y en aplicación de la doctrina sentada en su pro-

83 Así afirmará: “Una vez declarada la inconstitucionalidad y la derogación de tales preceptos, no por ello podrá afirmarse que la legislación de régimen local se ajusta de forma positiva a los principios inspiradores de la CE, ya que ha sido dictada con anterioridad a la misma y, por consiguiente, sin poder tener en cuenta tales principios ni, en especial, la nueva distribución territorial del poder prevista en el Título VIII de la CE... Por ello debe afirmarse que tal ajuste se producirá cuando el legislador dicte una nueva legislación de régimen local, de acuerdo con el mandato implícito que puede deducirse de los artículos 148.1 .2 y 149.1.18 de la propia CE. Mientras tanto si en el futuro...". 
pio pronunciamiento, el juez ordinario podía perfectamente establecer en sus sentencias la derogación de aspectos parciales del sistema normativo local. En este contexto, la "invitación" del TC al planteamiento de cuestiones por parte de los órganos judiciales no puede entenderse más que como una sugerencia a los mismos de que forzaran, elevando la cuestión, pronunciamientos de inconstitucionalidad sobre la materia que, dado su origen, tendrían efectos "erga omnes" con lo que ello implicaría de mejora de la seguridad jurídica frente a la opción de múltiples sentencias parciales de derogación por parte de la jurisdicción ordinaria, de valor tan sólo «inter partes». La propia sistematicidad del régimen local parecía hacer aun más aconsejable la primera opción.

Por último, el TC introduce la definitiva matización de que en el planteamiento de nuevos casos concretos se pudieran "apreciar nuevos matices en orden a justificar la oposición -o la disconformidada la CE". Con esta precisión el Tribunal parecía indicar la necesidad de alguna variación en la motivación o en la causa de impugnación para la reproducción del juicio de constitucionalidad.

Curiosamente no volvemos a encontrar un pronunciamiento explícito sobre el art. 38.2 hasta la STC 20/88, es decir hasta siete años después. También aquí nos hallamos ante un caso peculiar, en cuanto la hipotética oposición entre el pronunciamiento desestimatorio $y$ el nuevo planteamiento, no se produce por la presentación de una $\mathrm{Cl}$ tras una sentencia desestimatoria del recurso, sino por la interposición de un $\mathrm{Rl}$ que técnicamente parecía implicar la repetición del examen de constitucionalidad realizado en la sentencia desestimatoria de un procedimiento de control previo de constitucionalidad. Ante la impugnación del art. 15.2 de la Ley del Proceso Autonómico de 1983 por el gobierno catalán, el abogado del Estado aducirá que este juicio de conformidad con la Constitución ya se había producido en la STC 76/83 (la famosa sentencia sobre la LOAPA), resultado de un control previo, y realizará una interpretación del art. 38.2 LOTC tendente a aplicar semejante disposición "por analogía" a las sentencias desestimatorias de los recursos previos. EI TC, tras rechazar de raíz semejante analogía, al subrayar las diferencias teleológicas y funciones básicas entre el, ya en ese tiempo derogado, recurso previo y el recurso de inconstitucionalidad 84 , precisará explícitamente que «debe afirmarse que el art. 38.2 se refiere sólo a las sentencias desestimatorias dictadas en recur-

84 «No son, o no eran, procesos iguales ni en su objeto ni en su tramitación, ni tampoco en los efectos previstos en el art. 38 de la LOTC, mientras que las sentencias dictadas en los procesos de recurso previo quedaban sujetas, en cuan- 
sos directos de inconstitucionalidad, quedando fuera del efecto impeditivo que dicho precepto consagra, tanto las sentencias dictadas en el recurso previo de inconstitucionalidad -que es, como queda dicho, un proceso distinto al del recurso directo- como la vía indirecta de la cuestión de inconstitucionalidad que los órganos judiciales pueden plantear ante este Tribunal cuando alberguen dudas acerca de la validez de la norma legal aplicable al caso y de la cual dependa el fallo que haya de dictar». Posteriormente mantendrá que la "misma vía» de control a la que el propio artículo $\mathbf{3 8 . 2}$ se refiere, esto es, la vía del recurso directo de inconstitucionalidad frente a leyes publicadas $y$ en vigor, es el alcance del límite obstativo que establece el art. 38.2.

En esta sentencia, por tanto, y ya en 1988, el TC, forzado por el intento de aplicación analógica realizado por el abogado del Estado, realiza una interpretación explícita del art. 38.2 LOTC, en cuanto señala como único límite consagrado en él, la interposición de un segundo recurso de inconstitucionalidad. En su sentencia el Tribunal se mueve permanentemente en el ámbito de la compatibilidad de procedimientos, sin entrar nunca en precisiones sobre los concretos límites de los pronunciamientos desestimatorios y configurando la compatibilidad entre el $\mathrm{RI}$ y la $\mathrm{Cl}$ como una "posibilidad de planteamiento" de la cuestión por parte del juez ordinario.

El siguiente paso importante en la interpretación del art. 38.2, y aparte de los Autos 352/90 y 93/91 que más adelante veremos, lo da el TC en su sentencia $9 / 93^{85}$. Ante las objeciones del abogado del Estado de que el Tribunal ya se había pronunciado sobre la premisas que fundamentaban en último extremo la duda de constitucionalidad en la STC 37/87 que rechazó un anterior recurso ${ }^{86}$, el TC afirmará que «a este respecto, basta decir que la existencia de aquel pronunciamiento ante-

to a su eficacia, a las reglas singulares recogidas en los apartados 4 y $\mathbf{5}$ del artículo 79. Esta diferencia de tratamiento legal, que es una consecuencia lógica de la distinta naturaleza de uno y otro tipo de proceso constitucional, está por lo demás inequívocamente reflejada en el tenor de los arts. 38.2 y 79.5 de la LOTC". FJ 2. En este mismo fundamento el TC realizará una interpretación sobre el derogado art. 79.5 de la LOTC, donde deja claro que precisamente una de las características del control previo era no excluir, como por otra parte, dado el tenor de los arts. 161.1. a) y 163 de la CE no podía hacer, el control posterior de la ley en vigor a través de los procedimientos del $\mathrm{RI}$ y la $\mathrm{Cl}$.

85 Se trataba de una $\mathrm{Cl}$ planteada contra el art. 19.1 de la Ley de Reforma Agraria de Andalucía de 1984 que es resuelta de forma desestimatoria por el TC.

86 Si la llamada "expropiación-sanción" constituía o no un sanción en el sentido del art. 25.1 de la CE. 
rior del Tribunal no hace inviable, sin más, la presente cuestión, pues el art. 38.2 LOTC permite la sucesión entre recurso desestimado y cuestión de inconstitucionalidad sobre igual objeto, esto es, frente al mismo precepto legal y con fundamento en la infracción de idéntico precepto constitucional. Y ello con independencia de que el Tribunal a quo, en este caso, ha argumentado que plantea su duda desde un enfoque o perspectiva no considerado en su momento, por la STC $37 / 87$. Sea esto o no así, también es preciso subrayar que la posibilidad que abre el citado art. 38.2 de nuestra ley orgánica no exime a los órganos judiciales, claro está, del deber que sobre ellos pesa de atenerse a la doctrina constitucional que derive de las sentencias dictadas por este Tribunal (arts. 164.1 CE, 40.2 LOTC y 5.1 LOPJ)".

Varios aspectos resultan interesantes del que es el pronunciamiento más claro del Tribunal Constitucional sobre la compatibilidad entre el recurso y la cuestión de inconstitucionalidad. En primer lugar el carácter de "obiter dicta" del propio pronunciamiento, lo que sin duda ha permitido una mayor libertad "expresiva" al TC. El propio Tribunal admite en primer lugar que las objeciones de admisibilidad presentadas, $y$ en concreto el "fundamento de la duda de inconstitucionalidad" en cuanto al carácter de la "expropiación-sanción" son de tal entidad, que resulta de ellos «una imposibilidad de separar estas objeciones del fondo de la cuestión misma», por lo que "la respuesta específica a dichos alegatos se hará con ocasión del examen de cada uno de los reproches de inconstitucionalidad de que ha sido objeto el precepto cuestionado...". "En otras palabras, no estamos ante posibles causas de inadmisión de esta cuestión, sino ante argumentos que habrían de conducir, de tener razón jurídica, a su desestimación. No obstante, importa dar por sentada una consideración de principio... No cabe por último dejar de recordar...", y a continuación las frases sobre el art. 38.2 transcritas anteriormente.

EI TC admite por tanto que la "sustancialidad" del argumento de constitucionalidad alegado por el órgano judicial y su consideración diferente al estudiado en la STC 37/87, van a ser elementos posteriores de juicio para determinar el fondo de la resolución. En estas condiciones mal cabría apreciar un obstáculo de admisión basado en una identidad de motivos que, en el fondo, va a ser uno de los temas de fondo de la sentencia ${ }^{87}$. De ahí que las rotundas afirmaciones de la sen-

87 El propio órgano judicial alegaba que en la sentencia 37/87 se consideró el art. 19 desde la perspectiva de la constitucionalidad de la «causa expropian- 
tencia hayan de interpretarse a la luz de la compatibilidad o no de ambas vías de acceso, compatibilidad que en este caso queda meridianamente establecida ${ }^{88}$, y no bajo el prisma de la posibilidad o no de enjuiciamiento de problemas "idénticos», como podría deducirse de una primera lectura del FJ 1. Esta óptica se refuerza con la expresión del propio TC al afirmar que "la existencia de un pronunciamiento anterior del Tribunal no hace inviable, sin más, la presentación de la cuestión". El Tribunal deja abierta la puerta, creemos, a que permitida la presentación de la cuestión, ésta sin embargo sea inviable. De ahí la referencia, si bien confusa, al hecho de que el órgano judicial haya argumentado que planteaba su duda "desde una perspectiva 0 enfoque no considerado".

Una posterior mención significativa al art. 38.2, en un pronunciamiento sobre una cuestión, se producirá en la STC 55/96 sobre la Ley Orgánica de Regulación de los Recursos sobre la objeción de conciencia de 1984. El Tribunal Constitucional señala que en el RI que dio origen a la STC 160/87 presentado por el Defensor del Pueblo "ya figuraba un motivo parcialmente coincidente con el contenido de las cuestiones de inconstitucionalidad que ahora abordamos". El TC entra sin embargo a conocer de la cuestión ${ }^{89}$, teniendo en cuenta que uel nuevo cuestionamiento del art. 2.3...se produce por vía distinta de la resuelta en la STC 160/87 (art. 38.2 LOTC); el que los motivos de incompatibilidad alegada no son totalmente coincidentes; $y$, por último, que las cuestiones objeto del presente proceso constitucional no adolecen, por reiterativas, de notoria falta de fundamento, ya que resulta relevante el lapso de tiempo transcurrido desde que se dictó la STC 160/87, a la vista de la actividad normativa y del intenso debate político y social que han tenido por objeto la institución de la prestación social sustitutoria y la respuesta jurídica anudada a la negativa a realizarla".

di", mientras que según su razonamiento es una garantía de procedimiento. Siendo por tanto igual uno de los preceptos constitucionales alegados, el art. 25.1, lo cierto es que la interpretación del art. 19.1 de la Ley variaba radicalmente.

88 Cabe destacar la progresiva evolución en los términos empleados por el TC acerca del art. 38.2. Si en la anterior STC 20/88 se establecía que el art. 38.2 "deja fuera del efecto impeditivo...", en la sentencia $319 / 93$ se habla ya claramente de que el art. 38.2 "permite...".

89 A pesar de las peculiaridades de la misma, al tratarse de una norma "abocada a su perentoria extinción a la vista del principio de retroactividad de la causa penal más favorable". 
Varias puntos resultan especialmente interesantes en este pronunciamiento. En primer lugar destaca el hecho de que, a estas alturas, el TC dé por supuesto que el artículo 38.2 tan sólo impide el replanteamiento del recurso, y que por tanto implícitamente permite un replanteamiento en otra vía. Lo que era objeto de expresa y contundente declaración en las STC 20/88 o 319/93, se convierte aquí en algo obvio, no necesitado de más fundamentación que la mera mención del artículo en cuestión. En segundo lugar, es necesario subrayar que el Tribunal Constitucional no considere suficiente explicación la mera existencia de una distinta vía para aceptar entrar en el fondo de la cuestión, sino que pase a explicitar inmediatamente que además de ser una vía distinta nos encontramos aquí con unos motivos de inconstitucionalidad "no totalmente coincidentes", lo que obviamente descarta el hecho de que nos encontremos ante problemas de constitucionalidad realmente "idénticos". Por último es importante la mención del Tribunal a la transformación del "problema constitucional" como consecuencia del cambio de circunstancias. Cambio que se entiende de una manera amplia (actividad normativa que modifica el "contexto legal» pero también "intenso debate político y social» que modifica el "contexto social" en el que debe interpretarse el primero), y que justifica su criterio de no encontrarnos ante cuestiones "reiterativas" ${ }^{90}$.

Cabe señalar, en otro orden de cosas, que existen pronunciamientos del Tribunal Constitucional relacionados con la compatibilidad entre las dos vías de acceso, donde sin mencionar al artículo 38.2, y dando por presupuesta esta compatibilidad, se pasa a analizar la existencia o no de un efecto de cosa juzgada de las sentencias constitucionales. En las STC $166 / 86$ y 6/91, producto ambas de cuestiones de inconstitucionalidad en relación al llamado "Caso Rumasa" (Ley $7 / 83$, de 29 de junio), se analizará la identidad entre el "objeto" de las impugnaciones ${ }^{91}$, o bien entre los preceptos constitucionales ale-

90 Es relevante también la mención que realiza a que estos cambios suponen que la cuestión no incurra en una "notoria falta de fundamento", expresión que cabría entender a la luz de los Autos 352/90 y 93/91 en un sentido rigurosamente técnico-procesal, es decir no cabría alegar el motivo del art. 37.1 para haber dado lugar a la apertura de un "trámite de inadmisión" con audiencia del Ministerio Fiscal.

91 Es el caso de la STC 166/86, donde ante la posibilidad de un efecto de CJ de la STC 111/83, que el TC se plantea, se afirma que "aunque parece darse este efecto, ello no es así porque en el F.J.3 de la primera sentencia se excluye expresamente del objeto del recurso de inconstitucionalidad el tema de la constitucionalidad de la expropiación "ope legis» que es el que aquí se trata". 
gados $^{92}$, para determinar, al comprobar que tales identidades no se producen, que «no puede apreciarse ningún obstáculo estrictamente procesal que se oponga al análisis de los temas ahora suscitados" (STC 6/91). Lo que parece indicar que no bastaría la mera diferencia entre las vías de acceso para eliminar cualquier posible efecto de la cosa juzgada del pronunciamiento anterior.

Por otra parte el TC reiterará su interpretación del artículo 38.2 como mero límite obstativo a la presentación de sucesivos recursos de inconstitucionalidad en la STC 13/84. En ella el Alto Tribunal al resolver un recurso de amparo y plantearse la posible inconstitucionalidad de la normativa legal que tuvo que aplicar el juez "a quo" ${ }^{93}$, mantiene que el hecho de que semejante normativa no fuese declarada inconstitucional con ocasión de una sentencia de un recurso de inconstitucionalidad anterior ${ }^{94}$ no impide que tal constitucionalidad no pueda ser de nuevo cuestionada en ese momento, "toda vez que lo que el art. 38.2 de la LOTC veda es el ulterior planteamiento de la cuestión en la misma vía fundado en infracción de mismo precepto constitucional y no en vía distinta como es la actual del amparo". No deja sin embargo el TC de matizar que, además, el precepto legal ahora cuestionado «no fue objeto concreto del análisis del Tribunal en aquella ocasión".

92 Así en la STC 6/91, FJ 4, donde se rechaza «la alegación formal de cosa juzgada material, en su sentido propio de excepción procesal», basándose en que en la sentencia 166/86 el tema se resolvía en relación al art. 24.1 CE, mientras que en esta sentencia, el órgano judicial la planteaba respecto de los artículos $33.3 \mathrm{y}$ 14 de la CE.

93 El recurso de amparo había sido presentado por una trabajadora cuya participación en un día de huelga la había privado del periodo necesario de seis meses para cobrar el subsidio de desempleo, habiendo cotizado por tanto,en virtud del art. 6.3 del Real Decreto Ley de 4 de marzo de 1977 que establecía la suspensión de la cotización en caso de huelga, 180 dias frente a los 181 exigibles por la ley $51 / 80$ en relación con el Real Decreto $929 / 81$ sobre prestaciones por desempleo. El TC señala que desde el punto de vista estrictamente jurídico la única manera de abordar el recurso de amparo consistiria en superar la individualidad del caso, con su "desafortunada suma de circunstancias", y plantearse desde una perspectiva más amplia la constitucionalidad del art. 6.3 del Real Decreto Ley 4/77 sobre relaciones de trabajo, en cuanto pudiera existir un principio en virtud del cual «la suspensión de la cotización durante la huelga o la falta de asimilación a día cotizado se considere incompatible con el derecho constitucional de huelgan.

94 STC 11/81, de 8 de abril, donde, en un fallo de pronunciamientos interpretativos y meramente desestimatorios, se pronuncia sobre gran parte de los artículos del Decreto Ley, pero no sobre el art. 6.3, cuya inconstitucionalidad nunca fue alegada por los 50 Diputados del Grupo socialista que presentaron el recurso. 
Si la jurisprudencia analizada hasta el momento, toda ella sobre supuestos de compatibilidad entre vías distintas de cuestionamiento de la ley, parece dejar claro el significado que el Tribunal Constitucional atribuye al art. 38.2 de la LOTC y, por ende, la ureducción interpretativa" operada implícitamente sobre el art. 29.2, no deja de ser cierto, sin embargo, que determinados pronunciamientos del Tribunal en los supuestos de reiteración de la misma vía procesal, implican, por el contrario, un cierto oscurecimiento en el alcance del art. 38.2.

La cuanto menos ambivalente postura del TC acerca de la reiteración de similares cuestiones de inconstitucionalidad excede del estricto ámbito de la compatibilidad entre las dos vías de acceso al control de la ley 95 , pero hay que señalar aquí que, en determinados autos del Tribunal ${ }^{96}$, éste, al inadmitir por "notoriamente infundadas" (vía art. 37.1 LOTC), cuestiones idénticas a otras ya resueltas en sentido negativo, si bien tras el auto de planteamiento del juez a quo, emplea como uno de sus argumentos el hecho de que "la reiteración de procesos con el mismo objeto y por las mismas razones sólo está vedada en el caso de los RI (art. 38.2 LOTC)".

Independientemente de la utilidad frente a otros expedientes técnicos y del juicio crítico que pueda merecer la inadmisión por "noto-

95 Sobre la problemática posibilidad de la repetición de cuestiones sus: tancialmente iguales, vid. JIMÉNEZ CAMPO, "Qué hacer con la ley inconstitucional», en La sentencia sobre la inconstitucionalidad de la ley, op. cit., págs. 27 y 28 , donde señala que el Tribunal no ha tenido ocasión de pronunciarse en este punto "y acaso no la encuentre nunca, pues es claro que una reformulación, por leve que sea, en el planteamiento de la nueva $\mathrm{Cl}$ deshace el problema». De ahí que califique el asunto como "casi exclusivamente académico». No obstante no deja de reconocer que el recurso del Tribunal a fallos de inadmisión de la $\mathrm{Cl}$, y cita una abundante jurisprudencia al respecto, puede hacer pensar en una opción del TC por la existencia de un efecto de cosa juzgada. Para Gómez MONTORO, "Art. 38", en Comentarios..., op. cit., págs. 575-6, la posibilidad de una cuestión tras la desestimación de otra idéntica sería posible dado el silencio al respecto del art. 38.2 LOTC y la necesidad de no cerrar el camino a una evolución de la jurisprudencia, donde además el TC podría considerar «que en un proceso posterior se planteen unas consecuencias que no pudieron ser tenidas en cuenta en el momento de dictar la primera sentencia». Aunque reconoce que hasta el momento el TC no ha admitido ninguna cuestión de inconstitucionalidad frente a una norma que ya hubiera sido objeto de otra, cree que las consideraciones recogidas en la STC 20/88, que ya comentamos, permitirían entender que el Tribunal acepta en el fondo esta posibilidad.

96 Señaladamente en los AATC 352/90, y 93/91, FJ único, en una línea que, como señalaba Gómez MonToro, "Art. 38", Comentarios..., op. cit., pág. 564, "sin embargo no se ha impueston. 
riamente infundada" de este tipo de cuestiones ${ }^{97}$, parece claro, sin embargo, que la afirmación del Tribunal, al hilo de tal utilización del art. 27.2, posibilita una interpretación extensiva del art. 38.2 LOTC muy superior a la mantenida en el resto de su jurisprudencia.

No es lo mismo afirmar que la prohibición que establece dicho artículo de que tras la sentencia desestimatoria de un recurso se interponga otro alegando el mismo precepto constitucional, supone, como contrapunto, que sí puede presentarse una cuestión de inconstitucionalidad, a dejar entender que dicha prohibición implica que sólo para el recurso se impide reiterar procesos exactamente idénticos.

En el primer caso, en la interpretación consolidada del Tribunal, nos encontramos con un problema de compatibilidad donde, de la prohibición de planteamiento en una misma vía, el Tribunal Constitucional deduce la posibilidad de planteamiento en una vía distinta. Se reafirma así, mediante una exégesis legal, la posibilidad que implícitamente parece deducirse del texto del artículo 38.2, y se obvia su posible incompatibilidad con el art. 29.2.

En el segundo caso, la afirmación del Tribunal, con ocasión de la aplicación del art. 37.1 LOTC, se apoya en el límite establecido en el art. 38.2 a la repetición de recursos - que el segundo recurso de inconstitucionalidad se funde en un idéntico precepto constitucional一, para, en contra del sentido de la enmienda que introdujo la frase, que no puede ser otro que limitar la imposibilidad absoluta de repetición, deducir por el contrario, no sólo la posibilidad del planteamiento sucesivo de cuestiones de inconstitucionalidad, un supuesto al que la norma no se refiere explícitamente, sino incluso que la repetición pueda darse aunque las cuestiones sean idénticas. Ello daría pie para sostener, como hará algún autor ${ }^{98}$, que el art. 38.2 en el fondo está consagrando la falta de cosa juzgada de las sentencias desestimatorias de la cuestión de inconstitucionalidad, al no imponer ningún límite a las repeticiones de $\mathrm{Cl}$, y todo esto, deduciéndolo de un artículo que ni siquiera se refiere en ningún momento a las sentencias de la cuestión sino a las del recurso de inconstitucionalidad.

97 Vid. JIMÉNEZ CAMPO, "Qué hacer con la ley inconstitucional», op. cit., pág. 28, y GómEZ MONTORO, "Art 38», op. cit., pág. 564, con abundante jurisprudencia al respecto.

98 Señaladamente, MARín PAGeO, La cuestión de inconstitucionalidad en el proceso civil, op. cit. 


\section{CONCLUSIONES}

De todo lo expuesto anteriormente sobre los arts. 29.2 y 38.2 de la LOTC creemos que puede deducirse algún punto firme, útil para determinar los límites de la cosa juzgada y, por ello mismo, para diferenciar este instituto del resto de los efectos de la sentencia constitucional.

En primer lugar parece claro que, tal y como se desprende del proceso de elaboración de la LOTC, la intención del legislador al dar su redacción definitiva a los artículos citados fue variar sustancialmente el esquema previsto en el Proyecto de Ley presentado por el Gobierno. Si en el Proyecto, el sistema de relaciones entre las dos vías de control de la ley se articulaba sobre la prohibición sin matices de la repetición del recurso (art. 38.2 en su numeración actual), y la posibilidad compensatoria de planteamiento indefinido de la cuestión tras una primera impugnación directa (art. 29.2), las modificaciones introducidas en el Congreso pretendían mantener la prohibición de recursos sucesivos (si bien con la matización de que el precepto constitucional alegado fuese el mismo), pero impidiendo también el posible planteamiento de cualquier cuestión de inconstitucionalidad una vez desestimado el recurso sobre la misma ley, siendo este el sentido de la introducción de la frase "por razones de forma" en el art. 29.2 LOTC.

Desde un primer momento una corriente mayoritaria de la doctrina, se opuso frontalmente a esta solución. El grueso de las críticas se centró en el art. 29.2, de cuya redacción se desprendía una prohibición absoluta de replanteamiento de la inconstitucionalidad de la ley a través de la cuestión, prohibición que parecía contradecir a los criterios mínimos de funcionalidad de la jurisdicción constitucional y de la evolución de su doctrina. En consecuencia, se remarcó la oposición del art 29.2 a aquello que parecía deducirse de una interpretación "a contrario" del art. 38.2, y se señalaron distintas interpretaciones de ambos preceptos buscando su concordancia sobre la base, en la mayoría de los casos, de la compatibilidad entre las dos vías de acceso.

La propia ambigüedad del texto legal y la falta de una teoría generalmente aceptada sobre los límites y la propia existencia de la cosa juzgada en la sentencia constitucional, facilitó una imbricación de ambas cuestiones, la compatibilidad entre las dos vías y el efecto de cosa juzgada, que a su vez contribuyó notablemente a aumentar la diversidad de posturas doctrinales sobre el real significado de ambos mandatos de la LOTC. 
En la temprana sentencia 4/81 del Tribunal Constitucional, éste abría una vía a una interpretación del art. 38.2 de la LOTC que iría posteriormente confirmando a lo largo de una no muy numerosa serie de pronunciamientos. Del análisis de esta jurisprudencia puede deducirse que el TC opta claramente por permitir el planteamiento de sucesivas cuestiones de inconstitucionalidad tras una primera sentencia desestimatoria de un recurso. Para ello se centra en la interpretación estricta de la prohibición sobre la repetición de recursos de inconstitucionalidad que consagra el art. 38.2, de la que deduce la posibilidad del planteamiento de una $\mathrm{Cl}$ tras una sentencia desestimatoria del RI, en cuanto únicamente impide el planteamiento ulterior "por la misma vía". Esta toma de posición implica "obviar" la "ratio legislatoris" del art. 29.2 de su ley de funcionamiento, artículo al que significativamente no se alude en ninguno de sus pronunciamientos. Una interpretación coherente de la posición del TC lleva sin embargo a entender que, para el Alto Tribunal, de dicho artículo tan sólo puede realizarse una exégesis literal, según la cual la desestimación por razones de forma del recurso permite siempre el planteamiento de la cuestión. Sólo esta estricta interpretación del contenido normativo del art. 29.2 no es incompatible con la voluntad atribuida al art. 38.2 LOTC.

Pensamos por tanto que el Tribunal Constitucional sitúa correctamente el campo de actuación de los arts. 29.2 y 38.2 dentro del problema de la compatibilidad/incompatibilidad entre los procedimientos de declaración de inconstitucionalidad, evitando deducir de éstos, y su silencio es aquí muy significativo, cualquier conclusión sobre la distinta cuestión del efecto de cosa juzgada de las sentencias sobre la constitucionalidad de la ley. Los distintos matices que hemos ido observando en cada uno de sus pronunciamientos vienen a corroborar este planteamiento, que sin embargo encuentra su mejor demostración en la compatibilidad "prima facie" de cualquiera de las teorías explicativas de la cosa juzgada con las afirmaciones realizadas por el Tribunal. El hecho de que, tanto los autores que mantienen la existencia de un efecto de uiudicato" en todas las sentencias sobre el fondo, como aquellos que sostienen la existencia de limites específicos para la cosa juzgada constitucional, o incluso los que niegan la existencia de este mismo efecto en determinado tipo de pronunciamientos, utilicen en parte argumentos extraídos de la jurisprudencia del Tribunal sobre el art. 38.2, no deja de ser todo un síntoma de la insuficiencia de asentar sobre este artículo de la LOTC criterios generales en torno a uno de los efectos que el art. 164 de la Constitución atribuye al pronunciamiento constitucional. 
Creemos pues, que, frente al procedimiento utilizado por parte de la doctrina, los artículos 29.2 y 38.2 de la LOTC no constituyen una vía esclarecedora para la determinación del posible efecto de cosa juzgada de los pronunciamientos constitucionales $y$, menos aún, para negar su existencia. De ellos, y de la jurisprudencia sobre los mismos del Tribunal Constitucional, tan sólo puede obtenerse un punto firme en orden a una teoría explicativa del uiudicato" constitucional, la necesidad de que ésta no resulte incompatible con lo explícitamente afirmado por el Tribunal: la compatibilidad entre las dos vías de acceso a la hora de cuestionar la constitucionalidad de las normas con rango de ley. 